\title{
Performance Analysis and Optimization of an Ejector Refrigeration System Using Alternative Working Fluids under Critical and Subcritical Operation Modes
}

\author{
Aggrey Mwesigye and Seth B. Dworkin* \\ Department of Mechanical and Industrial Engineering \\ Ryerson University \\ 350 Victoria Street, Toronto, Canada \\ (*Corresponding author: seth.dworkin@ ryerson.ca)
}

\begin{abstract}
Ejector systems are receiving considerable attention due to their simplicity, lower maintenance requirements, use of low grade heat, longer lifespan and low cost. In this paper an improved model to predict the performance of an ejector refrigeration system under both the critical and subcritical modes of operation was developed and validated. The model predicts ejector performance more precisely compared to studies following the same modelling approach in the literature. Using the developed model, performances with environmentally benign refrigerants, including R1233zd(E), HFO1336mzz(Z), R1234ze(Z), R600, RE245fa2, and RE245fa2 as alternatives to R141b and $\mathrm{R} 245 \mathrm{fa}$ were investigated. For ejector area ratios between 4.45 to 12.98 , evaporator temperatures between $0^{\circ} \mathrm{C}$ and $16^{\circ} \mathrm{C}$ and condenser temperatures between 20 and $40^{\circ} \mathrm{C}$, the optimal performance of the ejector system was determined. Results show that for each refrigerant, higher area ratios give higher coefficients of performance, but require higher generator temperatures for better critical condensing temperatures. R600 showed the best performance followed by R1234Ze(Z) and $\mathrm{R} 1233 \mathrm{Zd}(\mathrm{E})$ for the entire range of parameters considered. Results further show that there is an optimum generator temperature at each area ratio that maximizes performance. The optimal generator temperature increases as the area ratio and the condensing temperature increase. An alternative and more convenient approach to optimize ejector performance has been suggested in this work.
\end{abstract}

Keywords: Area ratio, critical mode, ejector refrigeration system, entrainment ratio, loss coefficients, subcritical mode 


\section{Nomenclature}

\begin{tabular}{ll}
$a$ & Speed of sound, $\mathrm{m} \mathrm{s}^{-1}$ \\
$A$ & Area, $\mathrm{m}^{2}$ \\
$A_{3}$ & Mixing section cross-section area, $\mathrm{m}^{2}$ \\
$A_{p l}$ & Ejector nozzle exit area, $\mathrm{m}^{2}$ \\
$A_{t}$ & Nozzle throat area, $\mathrm{m}^{2}$ \\
$c_{p}$ & Specific heat capacity at constant pressure, $\mathrm{J} \mathrm{kg}^{-1} \mathrm{~K}^{-1}$ \\
$C O P$ & Coefficient of performance \\
$d$ & Diameter, $\mathrm{m}$ \\
$h_{e o}$ & Enthalpy at the evaporator outlet, $\mathrm{J} \mathrm{kg}^{-1}$ \\
$h_{e i}$ & Enthalpy at the evaporator inlet, $\mathrm{J} \mathrm{kg}^{-1}$ \\
$h_{g i}$ & Enthalpy at the generator inlet, $\mathrm{J} \mathrm{kg}^{-1}$ \\
$h_{g o}$ & Enthalpy at the generator exit, $\mathrm{J} \mathrm{kg}^{-1}$ \\
$h_{c o}$ & Enthalpy at the condenser exit, $\mathrm{J} \mathrm{kg}^{-1}$ \\
$\dot{m}$ & Mass flow rate, $\mathrm{kg} / \mathrm{s}$ \\
$M$ & Mach number \\
$P$ & Pressure, $\mathrm{Pa}$ \\
$P_{c}$ & Condensing/back pressure, Pa \\
$P_{e}$ & Evaporator pressure, Pa \\
$P_{g}$ & Generator pressure, Pa \\
$R$ & Gas constant, $\mathrm{J} \mathrm{kg}{ }^{-1} \mathrm{~K}^{-1}$ \\
$\dot{Q}_{e}$ & Rate of energy flow in the evaporator, $\mathrm{J} / \mathrm{s}$ \\
$\dot{Q}_{g}$ & Rate of energy flow in the generator, $\mathrm{J} / \mathrm{s}$ \\
$T$ & Temperature, $\mathrm{K}$ \\
$u$ & Velocity, $\mathrm{m} \mathrm{s}-1$ \\
$W_{p}$ & Pumping power, $\mathrm{J} / \mathrm{s}$ \\
\hline$r e k$ &
\end{tabular}

\section{Greek Symbols}

$\phi_{p} \quad$ Loss coefficient between the nozzle exit and mixing section

$\phi_{m} \quad$ Mixing loss coefficient

$\phi_{m p} \quad$ Mixing loss coefficient for the breakdown model

$\phi_{p} \quad$ Loss coefficient between the nozzle exit and mixing section

$k \quad$ Isentropic index

$\eta_{p} \quad$ Nozzle efficiency

$\rho \quad$ Density, $\mathrm{kg} \mathrm{m}^{-3}$

$\mu \quad$ Entrainment ratio 


$\begin{array}{ll}\text { Subscripts } & \\ c c & \text { Critical mode of operation } \\ c i & \text { Subcritical mode of operation } \\ c b & \text { Ejector breakdown point } \\ c & \text { Condenser } \\ e & \text { Evaporator } \\ g & \text { Generator } \\ m & \text { Mixing/mixed flow } \\ m 2 & \text { Mixed flow for the breakdown model } \\ p & \text { Primary flow } \\ p 1 & \text { Nozzle exit } \\ 2 p & \text { Primary flow at the mixing section } \\ 2 s & \text { Secondary flow at the mixing section } \\ s & \text { Secondary flow } \\ t & \text { Nozzle throat } \\ x p & \text { Primary flow at section } x \text { - } x \text {, only for the breakdown model } \\ x s & \text { Secondary flow at section } x \text { - } x \text {, only for the breakdown model } \\ 3 & \text { Diffuser inlet }\end{array}$




\subsection{Introduction}

\subsection{Background}

Heating, ventilation, air conditioning, and refrigeration (HVAC\&R) systems for residential and service sectors account for about $40 \%$ of the total primary energy supply in developed countries [1]. The continued reliance on fossil fuels to supply this energy leads to increased emission of $\mathrm{CO}_{2}$, and significantly accelerating global warming. Another drawback of the current HVAC\&R systems is the widespread use of the vapor compression cycle that uses electricity derived mainly from fossil fuels and refrigerants that are harmful to the environment. To reduce energy usage in HVAC\&R systems and subsequently curb $\mathrm{CO}_{2}$ emissions, there are several research and development initiatives toward sustainable, clean, and renewable energy systems. HVAC\&R systems that are less reliant on fossil fuels are increasingly being studied and developed. Systems requiring low grade energy from renewable energy resources or waste heat are especially receiving considerable attention. They include absorption refrigeration systems, adsorption systems, desiccant refrigeration systems and ejector refrigeration systems [2].

Among these systems, the ejector refrigeration system is a promising technology that is receiving considerable attention. It is simple, low cost, and does not have moving parts, thus highly durable and less costly to operate when compared to the vapor compression system [3]. Moreover, it can be activated by low grade heat available from several sources, including waste heat, solar energy, and biomass energy, making it easy to deploy in areas with no access to the grid. Several researchers have investigated the performance of ejector refrigeration systems. Both experimental and theoretical studies have been conducted. Modeling and simulation of ejector refrigeration systems provide a means of screening different ejector geometries and investigating performance under different working conditions with ease and at lower costs compared to experimentation. Several models have been proposed and developed for this purpose. Most of the studies are based on the 1-D model initially developed by Keenan et al. [4], who postulated that the pressure of the primary and secondary flow was equal at the nozzle exit and that the mixing of the two fluids begins at the start of the constant area section. This theory has been adopted widely in most research studies on ejector systems [5,6]. Table 1 highlights the experimental and theoretical studies on ejector refrigeration systems. 
Table 2. Experimental and theoretical studies on the performance of ejector refrigeration systems

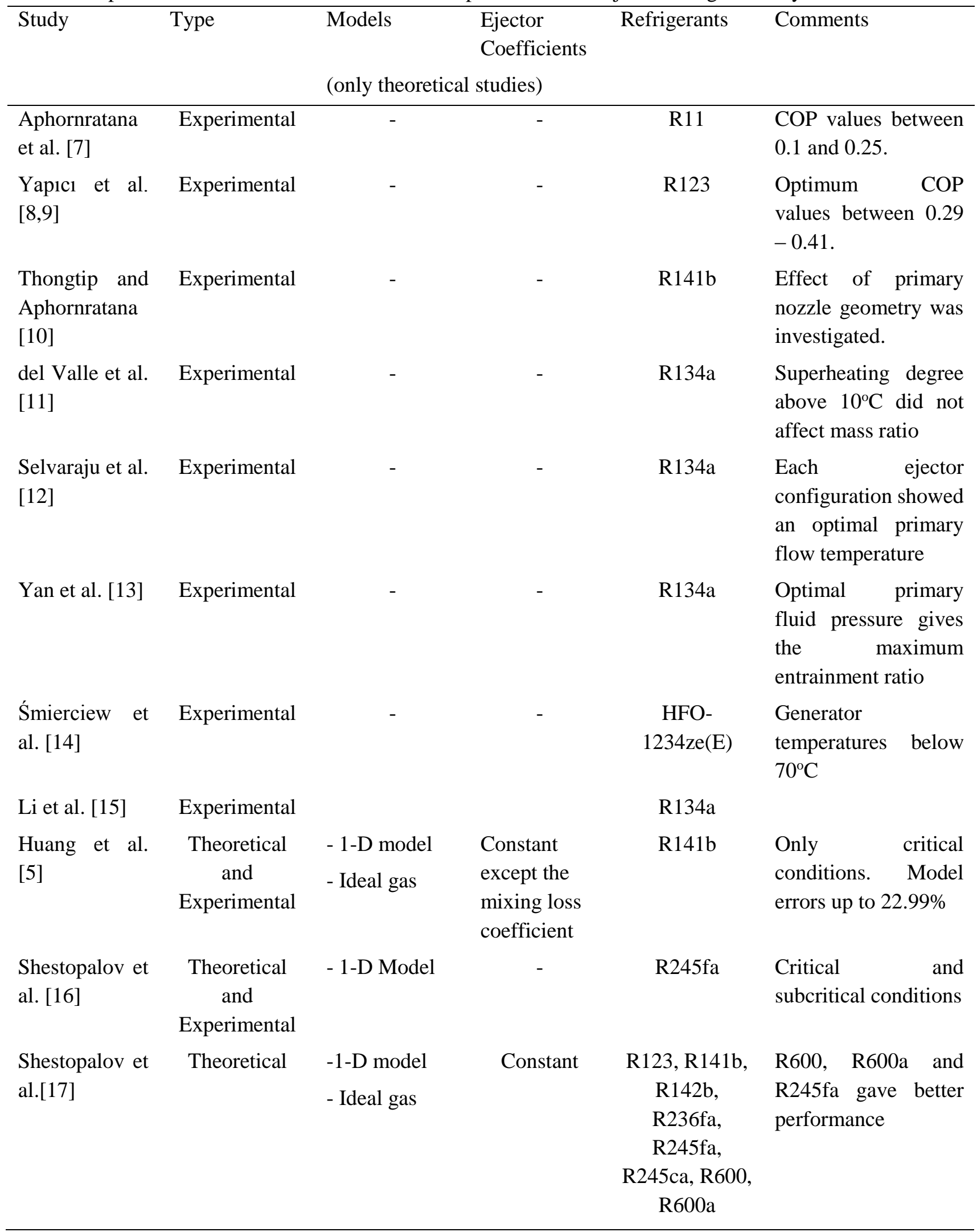




\begin{tabular}{|c|c|c|c|c|c|}
\hline Chen et al. [6] & Theoretical & $\begin{array}{l}\text {-1-D model } \\
\text { - Real gas } \\
\text { model }\end{array}$ & $\begin{array}{l}\text { Constant } \\
\text { ejector } \\
\text { efficiencies }\end{array}$ & $\begin{array}{l}\text { R123, R124, } \\
\text { R134a, R141b, } \\
\text { R142b, R152a, } \\
\text { R290, R600, } \\
\text { R600a and } \\
\text { R717 }\end{array}$ & $\begin{array}{l}\text { Critical and } \\
\text { subcritical } \\
\text { conditions. Errors up } \\
\text { to } 16.05 \%\end{array}$ \\
\hline $\begin{array}{l}\text { Chen et al. } \\
{[18]}\end{array}$ & Theoretical & $\begin{array}{l}\text { - 1-D model } \\
\text { - Ideal gas }\end{array}$ & $\begin{array}{l}\text { Constant } \\
\text { except the } \\
\text { mixing loss } \\
\text { coefficient }\end{array}$ & $\begin{array}{l}\mathrm{R} 141 \mathrm{~b}, \text { air and } \\
\text { propane }\end{array}$ & $\begin{array}{l}\text { Deviations up to } 15 \% \\
\text { for R141b, } 18 \% \text { for } \\
\text { air and } 16 \% \text { for } \\
\text { propane. }\end{array}$ \\
\hline $\begin{array}{l}\text { Ouzzane and } \\
\text { Aidoun [19] }\end{array}$ & Theoretical & $\begin{array}{l}\text { - 1-D model } \\
\text { - Real gas }\end{array}$ & - & $\mathrm{R} 142 \mathrm{~b}$ & $\begin{array}{l}\text { Discrepancies up to } \\
13 \% \text { for the off- } \\
\text { design conditions and } \\
\text { within } 8 \% \text { for optimal } \\
\text { conditions }\end{array}$ \\
\hline $\begin{array}{l}\text { Hassanain et } \\
\text { al. [20] }\end{array}$ & Theoretical & $\begin{array}{l}\text { - 1-D model } \\
\text { - Real gas }\end{array}$ & $\begin{array}{l}\text { Constant } \\
\text { isentropic } \\
\text { efficiencies }\end{array}$ & $\mathrm{R} 134 \mathrm{a}$ & $\begin{array}{l}\text { COP values within } \\
\pm 2.3 \%\end{array}$ \\
\hline Li et al. [21] & Theoretical & $\begin{array}{l}\text {-1-D Model } \\
\text { - Ideal gas } \\
\text { model }\end{array}$ & $\begin{array}{l}\text { Dependent } \\
\text { on area ratio } \\
\text { and pressure } \\
\text { ratio }\end{array}$ & $\begin{array}{l}\text { R141b, air, } \\
\text { R245fa }\end{array}$ & $\begin{array}{l}\text { Overall, better } \\
\text { prediction of ejector } \\
\text { performance, } \\
\text { deviations up to } \\
\pm 7.95 \%\end{array}$ \\
\hline Li et al. [22] & Theoretical & $\begin{array}{l}\text {-1-D Model } \\
\text {-Real gas }\end{array}$ & $\begin{array}{l}\text { Dependent } \\
\text { on area and } \\
\text { pressure } \\
\text { ratios }\end{array}$ & $\begin{array}{c}\text { R141b, } \\
\text { R245fa, R134a }\end{array}$ & 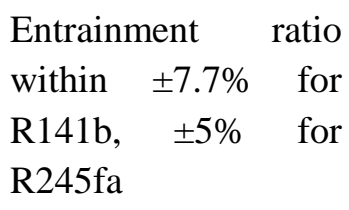 \\
\hline $\begin{array}{l}\text { Zegenhagen } \\
\text { and Ziegler } \\
{[23]}\end{array}$ & Theoretical & $\begin{array}{l}\text {-1-D Model } \\
\text { - Real gas }\end{array}$ & $\begin{array}{l}\text { Function of } \\
\text { local mixture } \\
\text { velocity }\end{array}$ & $\mathrm{R} 134 \mathrm{a}$ & $\begin{array}{l}\text { Experimental values } \\
\text { within } \pm 10 \% \text { average } \\
\text { arithmetic deviation } \\
\text { of } 7.8 \%\end{array}$ \\
\hline
\end{tabular}

As the reviewed studies in Table 1 show, in ejector modeling, the precise prediction of ejector performance requires correct specification of ejector loss coefficients. Most studies in the literature have used constant ejector loss coefficients with significant errors $[5,6,18]$. The recent works by Li et al. [21,22] indicated that these coefficients should be functions of the ejector area ratio and the ejector pressure ratio for improved accuracy. As the first objective of this study, correlations of the loss coefficients have been derived to improve the 1-D model in Huang et al. [5] following the same approach in this widely used model. In addition, a simpler and easier approach using non- 
linear regression is followed to determine the ejector coefficients compared to the more complicated sparsity-enhanced optimization technique in Li et al. [21].

\subsection{Review of studies on ejector systems using environmentally friendly working fluids}

The choice of working fluids (refrigerants) in ejector refrigeration systems plays a fundamental role in determining the system's performance. In addition to safety, toxicity, flammability and corrosivity considerations, the mounting regulatory pressure now dictates that high global warming potential (GWP) refrigerants are phased out [24]. Therefore, several researchers have looked at different environmentally benign working fluids for use in ejector systems over the years. Cizungu et al. [25] investigated the performance of an ejector refrigeration system working with 'environmentally benign' refrigerants including, R123, R134a, R152a, R717 and R11. R11 and R123 have since been banned owing to their ozone depletion potentials (ODP) being greater than zero [26], while R134a has a high GWP and in the process of being phased out [24]. Dahmani et al. [27] obtained ejector performance with R134a, R152a, R290 and R600a as working fluids. Kasperski et al. [28] studied the performance of an ejector system working using R236ea, R236ca, R245ca, R245fa, R356mfc, RC318, Acetone, Benzene, Cyclohexane, Cyclopentane and Toluene as working fluids. They relied on the Huang et al. [5] model which predicts ejector performance with significant errors. Chen et al. [29] considered performance of an ejector refrigeration system under overall working modes with R134a, R152a, R290, R430A, R245fa, R600, R600a and R1234ze as working fluids. The ejector component efficiencies were considered constant in the study.

Tashtoush et al. [30] examined the performance of an ejector system under superheated flow conditions with R152a, R290, R141b, R123, R600a, R600, R717 and R134a using a 1-D modeling approach based on the ideal gas model. They used the model proposed in Chen et al. [18] which gave significant deviations from experimental data. Roman and Hernandez [31] investigated an ejector system using R290, R152a, R134a, R600a, R600 and R123 as working fluids. The system with R290 had the highest COP while that with R123 gave the lowest COP. In a recent study, Gill and Kasperski [32] considered the use of ethers and fluorinated ethers as refrigerants in the ejector refrigeration cycle. They obtained maximum COP values of 0.30 and 0.25 for dimethyl ether and diethyl ether, respectively which have GWPs of 1 and 4, respectively [32]. Like their earlier study in Kasperski et al. [28], a computer program based on the modeling approach of Huang et al. [5] was used. 
From the above literature review, most of the earlier studies in the literature have considered refrigerants with high GWP or ones with ODPs greater than zero. Refrigerants R141b, R123, R245fa, and R134a have been widely considered as working fluids in the ejector refrigeration system. The first two are already banned [26], while the remaining two will be phased out soon [24]. R600, R600a and R290 have also been considered in theoretical studies as potential environmentally friendly refrigerants, but these are highly flammable.

There are increased research and development efforts to create environmentally benign working fluids. Hydroflouro olefin (HFO) refrigerants are a new generation of refrigerants with a very low GWP and no ODP $[33,34]$. As such, there is growing interest in their utilization in refrigeration systems. For ejector refrigeration systems, a recent study by Śmierciew [14] investigated the performance of HFO-1234ze(E) in an ejector refrigeration system driven by low grade heat with a heat source temperature of $70^{\circ} \mathrm{C}$ and thermal capacity of $90 \mathrm{~kW}$ to provide $30 \mathrm{~kW}$ of cooling. In another recent study, Atmaca et al. [35] compared the performance of an ejector refrigeration system using R1234yf, R1234ze(E) and R134a. The maximum COP was shown to be closer for R1234ze(Z) and R134a, but higher than that of R1234yf. In these studies, the potential for HFO refrigerants in ejector systems has been demonstrated.

Even though there is a considerable number of HFO refrigerants available today [33], studies on the performance of HFO refrigerants in ejector refrigeration systems are still limited in the literature. This is mainly because most HFO refrigerants have recently been introduced to the market [34,36,37]. Moreover, the few studies that considered HFOs relied on models that have been shown to give significant errors. Therefore, as these alternative working fluids are developed, there is a need to accurately characterize their performance in ejector refrigeration systems and other thermal systems.

\subsection{Purpose of this study}

The main purpose of this paper is to develop an improved model that accurately determines the performance of an ejector refrigeration system and use it to investigate and optimize performance with alternative environmentally benign refrigerants. In this study, the developed model predicts ejector performance for R141b, R245fa and similar dry and isentropic working fluids under both the critical and sub-critical modes of operation with significantly improved accuracy compared to the Huang et al. [5] and Chen et al. [18] models which use the same mathematical approach. Using 
the improved model, ejector performance with environmentally benign refrigerants, $\mathrm{R} 1233 \mathrm{zd}(\mathrm{E})$, HFO1336mzz(Z), R1234ze(Z), R600, and RE245fa2 has been undertaken. The HFO refrigerants, R1233zd(E), HFO1336mzz(Z), and R1234ze(Z) considered in this study have no ODP and significantly lower values of GWP, while RE245fa2 has a low GWP and no ODP. To the authors' knowledge, the performance of the ejector refrigeration systems using these HFO refrigerants has not been considered before. Moreover, optimization of ejector performance has not been widely reported in the literature. In this study, optimum generator temperatures, entrainment ratios, COP and critical condensing temperatures are obtained and presented for the considered area ratios.

\subsection{Ejector refrigeration system}

In an ejector refrigeration system shown in Fig.1, heat is added to the generator (boiler) to produce a high pressure and high temperature refrigerant vapour also called the primary or motive fluid. Generator temperatures between $70^{\circ} \mathrm{C}$ and $120^{\circ} \mathrm{C}$ can be used depending on the ejector geometry and the type of working fluid used. With no superheating of the primary flow exiting the generator, the generator pressure is usually the corresponding saturation pressure at the generator temperature considered, also dependent on the working fluid. The motive fluid enters the nozzle of the ejector and expands resulting in supersonic flow within a low-pressure [38]. This creates a partial vacuum which leads to entrainment of the secondary flow into the ejector from the evaporator.

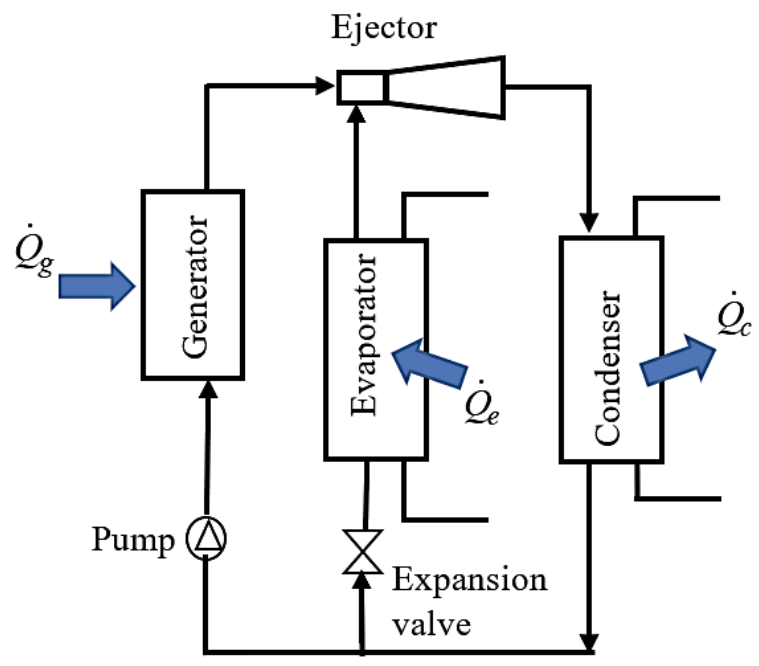

Fig. 1. Schematic representation of an ejector refrigeration system

The two flows combine in the mixing chamber of the ejector and discharge through the diffuser to the condenser (Fig.2). The vapor condenses back to liquid at ambient temperature and is returned 
to the boiler through a feed-pump. The remaining liquid is throttled to the evaporator using a throttle valve or an expansion device to complete the cycle. The energy transferred from the conditioned space to the evaporator creates the necessary cooling effect to maintain the required temperatures. The energy rejected as heat by the condenser can also be used for heating purposes as required.

The ejector is a central component to the performance of the entire system. Several studies are dedicated to the understanding of the involved complex phenomena. The ejector has three fundamental sections (suction chamber including the nozzle, constant area section and the diffuser section) in which suction, mixing and compression take place causing entrainment of the secondary flow, mixing with the primary flow and increase of pressure to condenser pressure, respectively. The different sections of the ejector are shown in Fig. 2.

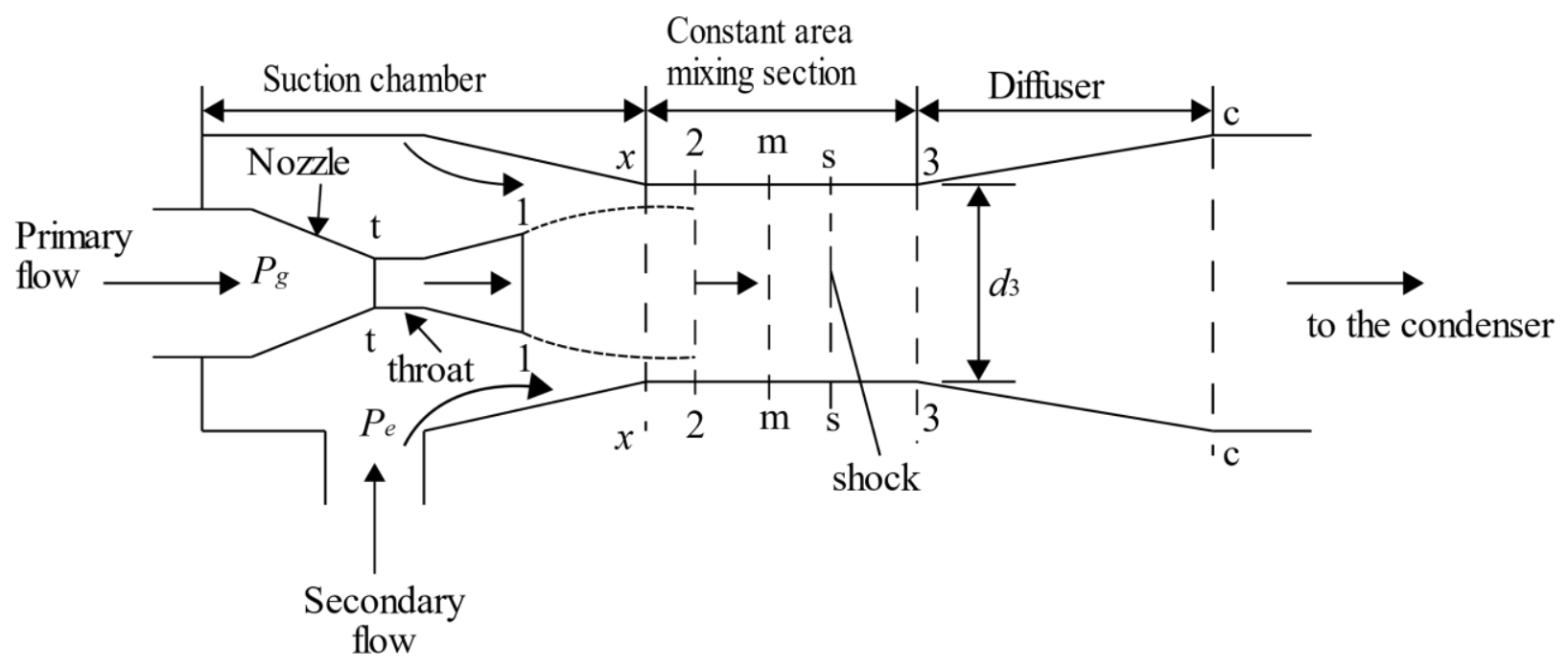

Fig. 2. Representation of the different sections of an ejector

\subsection{Theoretical model development}

The ejector model used in this work is based on the constant pressure mixing theory which is widely used in the study of ejector systems $[5,18,21]$. The model combines the approach used in Huang et al. [5] to determine performance in the critical mode of operation and the method used by $\mathrm{Li}$ et al. [21] to model the subcritical mode of operation and to determine the breakdown conditions. In addition, the correlations representing the ejector coefficients have been derived to improve the accuracy of the model. The detailed model is described in section 3.1. 


\subsection{Ejector model}

In the ejector, mixing takes place when the primary flow has been decelerated and the secondary flow has been accelerated to ensure complete mixing at equal pressures [4]. The following assumptions for the ejector shown in Fig. 2 and other components given in Fig. 1 have been adopted in this study:

i. The working fluid inside the ejector component is an ideal gas with temperature dependent specific heat capacities. For the evaporator, condenser, pump and generator, real fluid properties are used.

ii. The flow is steady and one-dimensional throughout the system.

iii. All components are taken to be well insulated and therefore adiabatic.

iv. The primary and secondary flows are saturated vapors at the exit of the generator and inlet to the nozzle, respectively.

v. The velocities of the primary flow and the secondary flow before entering the ejector nozzle are considered very small compared to the nozzle exit velocities.

vi. Constant pressure mixing occurs in the constant area section of the ejector under the critical operation mode.

vii. Each component in the ejector refrigeration system is a control volume.

The different modes of ejector operation are depicted in Fig.3. In the critical mode of operation, the entrainment ratio stays constant and the condensing pressure $\left(P_{c}\right)$ is lower than the critical condensing pressure $\left(P_{c c}\right)$. In the subcritical mode, the condensing pressure is between the critical condensing pressure and the breakdown pressure $\left(P_{c b}\right)$. In this mode, the entrainment ratio reduces as the condensing pressure increases until it reaches zero at the ejector breakdown pressure. Beyond the ejector breakdown pressure, there is backflow and the ejector malfunctions.

\subsubsection{Critical mode of operation}

In the critical mode of operation, both the primary flow and secondary flows are chocked. Using gas dynamics theory, the performance of the ejector can be determined using the following relations [5].

The mass flow rate of the primary flow through the nozzle is determined from [5] 


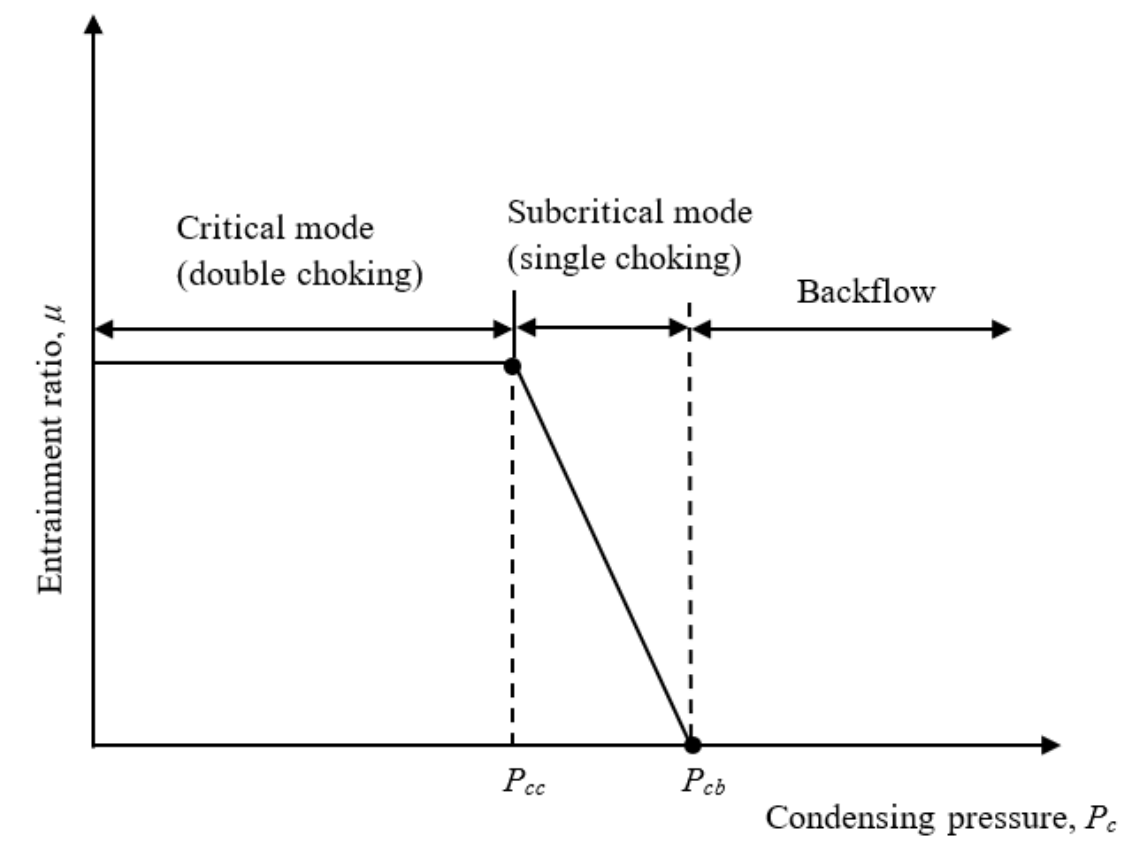

Fig. 3. Operation modes of an ejector

$$
\dot{m}_{p}=P_{g} \frac{A_{t}}{\sqrt{T_{g}}} \sqrt{\frac{k}{R}\left(\frac{2}{k+1}\right)^{(k+1) /(k-1)}} \sqrt{\eta_{p}}
$$

In Eqn. (1), $T_{g}$ is the generator temperature, $P_{g}$ is the generator pressure, $R$ represents the specific gas constant, $A_{t}$ is the nozzle throat diameter, $k$ is the heat capacity ratio also known as the isentropic index, and $\eta_{p}$ is the nozzle efficiency.

Another equation for flow through a supersonic nozzle suggested by Volovyk [39] and used in the study by Shestopalov et al. [17] is

$$
\dot{m}_{p, 1}=P_{g} \frac{A_{t} k}{\sqrt{\frac{2 k}{k+1} \frac{P_{g}}{\rho_{g}}}}\left(\frac{2}{k+1}\right)^{k /(k-1)} v
$$

The value of the correction factor, $v$ in Eqn. (2) was obtained from experimental results by Shestopalov et al. [17] as 0.95 .

The Mach number at the nozzle exit, $M_{p l}$ and the pressure at the nozzle exit, $P_{p l}$ for a known nozzle exit cross section area $A_{p l}$ can be approximated based on isentropic relations as [5] 


$$
\begin{aligned}
& \left(\frac{A_{p 1}}{A_{t}}\right)^{2} \approx \frac{1}{M_{p 1}^{2}}\left(\frac{2}{k+1}\left(1+\frac{k-1}{2} M_{p 1}^{2}\right)\right)^{(k+1) /(k-1)} \\
& \frac{P_{g}}{P_{p 1}} \approx\left(1+\frac{(k-1)}{2} M_{p 1}^{2}\right)^{k /(k-1)}
\end{aligned}
$$

The Mach number, $M_{2 p}$ and pressure $P_{2 p}$ of the primary flow at section 2-2 where mixing takes place are given as [5]

$$
\frac{P_{2 p}}{P_{p 1}} \approx \frac{\left(1+\frac{(k-1)}{2} M_{p 1}^{2}\right)^{k /(k-1)}}{\left(1+\frac{(k-1)}{2} M_{2 p}^{2}\right)^{k /(k-1)}}
$$

The area occupied by the primary flow at section $2-2, A_{2 p}$ is obtained according to

$$
\frac{A_{2 p}}{A_{p 1}} \approx \frac{\left(\phi_{p} / M_{2 p}\right)\left(\left(\frac{2}{k+1}\right)\left(1+\frac{(k-1)}{2} M_{2 p}^{2}\right)\right)^{(k+1) /(2(k-1))}}{\left(1 / M_{p 1}\right)\left(\left(\frac{2}{k+1}\right)\left(1+\frac{(k-1)}{2} M_{p 1}^{2}\right)\right)^{(k+1) /(2(k-1))}}
$$

In Eqn. (6), an arbitrary loss coefficient $\phi_{p}$ is specified to account for losses in the primary flow as it moves from the nozzle exit to the mixing section. This loss is said to be from slipping or viscous effects of the primary flow and the secondary flow at the boundaries [5].

The entrained flow from the inlet to the mixing section is characterized by assuming that it reaches the chocked condition at the mixing section. With this, the Mach number of the secondary flow is $M_{2 s}=1$. The pressure of the secondary flow at section 2-2 is given by

$$
\frac{P_{e}}{P_{2 s}}=\left(1+\frac{k-1}{2} M_{2 s}^{2}\right)^{k /(k-1)}
$$

The mass flow rate of the entrained secondary flow is obtained in a similar manner as the primary mass flow rate, but at the mixing section as

$$
\dot{m}_{s}=\frac{P_{e} A_{2 s}}{\sqrt{T_{e}}} \sqrt{\frac{k}{R}\left(\frac{2}{k+1}\right)^{(k+1) /(k-1)}} \sqrt{\eta_{s}}
$$


Where $\eta_{s}$ is the isentropic efficiency accounting for losses in the entrained secondary flow. The cross-sectional area at section $2-2$ is $A_{3}$; it is the sum of the areas covered by the primary flow, $A_{2 p}$ and the secondary flow, $A_{2 s}$ as

$$
A_{2 p}+A_{2 s}=A_{3}
$$

At mixing, the temperatures and Mach numbers of the two streams can be obtained from

$$
\frac{T_{g}}{T_{2 p}}=1+\frac{(k-1)}{2} M_{2 p}^{2}
$$

Equation 10 gives the temperature of the primary flow at mixing. For secondary flow, the mixing temperature is given by

$$
\frac{T_{e}}{T_{2 s}}=1+\frac{(k-1)}{2} M_{2 s}^{2}
$$

Once the streams are mixed, the conservation of momentum and energy give the velocity and the temperature of the mixed flow. The momentum balance results in

$$
\phi_{m}\left(\dot{m}_{p} u_{2 p}+\dot{m}_{s} u_{2 s}\right)=\left(\dot{m}_{p}+\dot{m}_{s}\right) u_{m}
$$

Where $u_{2 p}$ and $u_{2 s}$ are the velocities of the mixed flow at the mixing section, $u_{m}$ is the velocity of the mixed stream and $\phi_{m}$ is the loss coefficient which considers the losses due to friction. The energy balance equation is written as

$$
\dot{m}_{p}\left(c_{p} T_{2 p}+\frac{u_{2 p}^{2}}{2}\right)+\dot{m}_{s}\left(c_{p} T_{2 s}+\frac{u_{2 s}^{2}}{2}\right)=\left(\dot{m}_{p}+\dot{m}_{s}\right)\left(c_{p} T_{m}+\frac{u_{m}^{2}}{2}\right)
$$

The velocities at the mixing section are determined using the already-obtained Mach numbers and the speed of sound for each flow stream. For the primary flow at the mixing section

$$
u_{2 p}=M_{2 p} \times a_{2 p}
$$

Where $a_{2 p}$ is the speed of sound for the primary flow given by

$$
a_{2 p}=\sqrt{k R T_{2 p}}
$$

The velocity of the secondary flow at the mixing section is given by

$$
u_{2 s}=M_{2 s} \times a_{2 s}
$$

Where $a_{2 s}$ is the speed of sound for the secondary flow given by

$$
a_{2 s}=\sqrt{k R T_{2 s}}
$$

The Mach number of the mixed flow is obtained from 


$$
u_{m}=M_{m} \times a_{m}
$$

Where $a_{m}$ is the speed of sound of the mixed flow given by

$$
a_{m}=\sqrt{k R T_{m}}
$$

After the two fluids mix, a shock takes place with a sharp increase in pressure. For this supersonic shockwave and modelling the flow after the shockwave as isentropic, relations for the flow between section $\mathrm{m}-\mathrm{m}$ and the section downstream of the shock where the diffuser starts (section 3-3-) are obtained as

$$
\frac{P_{3}}{P_{m}}=1+\frac{2 k}{k+1} M_{m}^{2}-1
$$

And the Mach number at the diffuser inlet (section 3-3) is given as

$$
M_{3}^{2}=\frac{1+\frac{(k-1)}{2} M_{m}^{2}}{k M_{m}^{2}-\frac{(k-1)}{2}}
$$

Flow through the diffuser is also modeled by assuming an isentropic process. With this, the pressure at the diffuser exit is given as

$$
\frac{P_{c c}}{P_{3}}=\left(1+\frac{(k-1)}{2} M_{3}^{2}\right)^{k /(k-1)}
$$

With Eqns. (1) - (22), the performance of the ejector system operating under the critical mode is obtained. The resulting pressure in Eqn. (22) represents the critical condensing pressure and the corresponding saturation temperature is the critical condensing temperature. The entrainment ratio, $\mu$ is a critical parameter in characterizing ejector performance. The critical entrainment ratio, $\mu_{c c}$ is given by

$$
\mu_{c c}=\dot{m}_{s} / \dot{m}_{p}
$$

\subsubsection{Subcritical mode of operation}

As shown in Fig. 3, the entrainment ratio stays constant during the critical mode of operation. After the critical condensing pressure, the ejector performance begins to decrease until the breakdown pressure. At the breakdown pressure, it is no longer possible to entrain the secondary flow. Between the critical condensing pressure and the breakdown pressure, the ejector is operating in the subcritical mode and the entrainment ratio reduces from the critical value to zero at the 
breakdown pressure. To determine the performance of the ejector under off-design conditions, the breakdown modeling approach suggested in Li et al. [21] has been adopted in this work. This has been used together with the 1-D model from Huang et al. [5].

The relationship between primary flow pressure and Mach number at the inlet of the constant area section $(x-x)$ for the subcritical mode of operation is given by

$$
\frac{P_{g}}{P_{x p}}=\left[1+M_{x p}^{2}\left(\frac{k-1}{2}\right)\right]^{k /(k-1)}
$$

Where $P_{x p}$ is the pressure of the primary flow at section $x-x$ and $M_{x p}$ is the Mach number of the primary flow at section $x-x$.

At the breakdown point, there is no entrainment of the secondary flow, thus, the $\dot{m}_{x s}=0$ and the pressure of the secondary flow at section $x-x$ is the same as the evaporator pressure $\left(P_{x s}=P_{e}\right)$ [21]. We therefore have

$$
P_{x p}=P_{x s}=P_{e}
$$

The mass flow rate through the nozzle under subcritical conditions is the same as that in Eqn. (1). The temperature and the velocity of the primary flow at section $x$ - $x$ are obtained from [21]

$$
\frac{T_{g}}{T_{x p}}=1+M_{x p}^{2}\left(\frac{k-1}{2}\right)
$$

And

$$
u_{x p}=M_{x p} \sqrt{k R T_{x p}}
$$

Under subcritical flow conditions and at the breakdown pressure, the momentum balance gives

$$
\phi_{m p}\left(\dot{m}_{p} u_{x p}+\dot{m}_{x s} u_{x s}\right)=\left(\dot{m}_{p}+\dot{m}_{x s}\right) u_{m 2}
$$

Where $u_{m 2}$ simply represents the velocity of the flow after section $m-m$. At the breakdown point, there is no entrainment of the secondary flow and thus $\dot{m}_{x s}=0$. Even though Li et al. [21] suggest using a very small value of the secondary flow rate i.e. $\dot{m}_{x s}=10^{-6} \mathrm{~kg} / \mathrm{s}$, in the present model, a secondary mass flow rate of zero worked well without any convergence problems. The losses from section $x$ - $x$ to section $m-m$ in the subcritical mode are accounted for by the loss coefficient $\phi_{m p}$. The energy balance from $x-x$ to $m-m$ is 


$$
\dot{m}_{p}\left(c_{p} T_{x p}+\frac{u_{x p}^{2}}{2}\right)+\dot{m}_{x s}\left(c_{p} T_{x s}+\frac{u_{x s}^{2}}{2}\right)=\left(\dot{m}_{p}+\dot{m}_{x s}\right)\left(c_{p} T_{m 2}+\frac{u_{m 2}^{2}}{2}\right)
$$

The temperature of the secondary flow under the subcritical mode at section $x-x$ is given by

$$
\frac{T_{e}}{T_{x s}}=1+M_{x s}^{2}\left(\frac{k-1}{2}\right)
$$

Where

$$
u_{x s}=M_{x s} \sqrt{k R T_{x s}}
$$

And

$$
\frac{P_{x s}}{P_{e}}=\left(1+M_{x s}^{2}\left(\frac{k-1}{2}\right)\right)^{k /(1-k)}
$$

At section $m-m$

$$
u_{m 2}=M_{m 2} \sqrt{k R T_{m 2}}
$$

From section $m-m$ to the diffuser entry,

$$
\frac{P_{32}}{P_{m 2}}=1+2\left(\frac{k}{k+1}\right)\left(M_{m 2}^{2}-1\right)
$$

And

$$
M_{32}^{2}=\frac{1+\left(\frac{k-1}{2}\right) M_{m 2}^{2}}{k M_{m 2}^{2}-\frac{(k-1)}{2}}
$$

At the exit of the diffuser, the pressure is given as

$$
\frac{P_{c b}}{P_{32}}=\left[1+M_{32}^{2}\left(\frac{k-1}{2}\right)\right]^{k /(k-1)}
$$

In Eqns. (33) to (36), an additional subscript '2' (i.e. $P_{32}, M_{32}, M_{m 2}$ etc) is used to distinguish these equations from those for the critical mode of operation in obtaining the subcritical solution.

From Eqn. (36) the pressure at the breakdown point is obtained and used to determine the entrainment ratio for the ejector under the subcritical mode of operation as.

$$
\mu_{c i}=\mu_{c c} \frac{P_{c b}-P_{c}}{P_{c b}-P_{c c}}
$$

Where, $P_{c}$ is the condenser pressure under consideration. 


\subsubsection{Proposed correlations of the model coefficients}

One of the significant contributions of this work is the development of model coefficients that result in increased accuracy of the 1-D theoretical model for ejector analysis. These coefficients were mostly taken as constant in earlier studies such as Huang et al. [5], Chen et al. [18] and Chen et al. [40] giving significant errors. In line with recent studies [21,22], correlations of ejector coefficients have been developed as functions of the generator and evaporator pressure ratio and the ejector area ratio. For R141b, results in Huang et al. [5] have been used to derive the correlations using regression analysis. The loss coefficient in Eqn. (6) was found to be mainly a function of the ejector area ratio $\left(A_{r}=A_{3} / A_{t}\right)$ and the pressure ratio $\left(P_{g} / P_{e}\right)$ according to

$$
\phi_{p}=0.836+0.02656 \frac{A_{3}}{A_{t}}-0.01272 \frac{P_{g}}{P_{e}}
$$

The loss coefficient for the mixing process in Eqn. (12) was determined to be

$$
\phi_{m}=0.9573-0.01588 \frac{A_{3}}{A_{t}}+0.006627 \frac{P_{g}}{P_{e}}
$$

The results in Huang et al. [41] were used to obtain an approximate correlation for the loss coefficient for the breakdown model found in Eqn. (28) as

$$
\phi_{m p}=0.7938-0.03511 \frac{A_{3}}{A_{t}}+0.01231 \frac{P_{g}}{P_{e}}
$$

Equations (38) to (40) are valid for $6.44 \leq A_{3} / A_{t} \leq 10.64$, evaporator temperatures of $8^{\circ} \mathrm{C}$ and $12^{\circ} \mathrm{C}$, and $78^{\circ} \mathrm{C} \leq T_{s} \leq 95^{\circ} \mathrm{C}$.

The results in Shestopalov et al. [17] for different nozzle geometries using R245fa as the working fluid, were used to determine the loss coefficients. The loss coefficient in Eqn. (6) was determined to be

$$
\phi_{p}=0.8279+0.00161 \frac{A_{3}}{A_{t}}+0.00527\left(\frac{P_{g}}{P_{e}}\right)^{k}
$$

The loss coefficient in Eqn. (12) was obtained as

$$
\phi_{m}=0.9303-0.005519 \frac{A_{3}}{A_{t}}+0.00006586\left(\frac{P_{g}}{P_{e}}\right)^{k}
$$

For the breakdown model, the loss coefficient in Eqn. (28) was also determined based on data available in Shestopalov et al. [16,17] as 


$$
\phi_{m p}=0.7708-0.0612 \frac{A_{r}}{A_{r t}}+0.001209\left(\frac{P_{g}}{P_{e}}\right)^{k}
$$

Where $A_{r t}$ is the ratio of the ejector exit area to ejector throat area $\left(A_{1} / A_{t}\right)$.

Equations (41) to (43) are valid for $7.25 \leq A_{r} \leq 12.89,8^{\circ} \mathrm{C} \leq T_{e} \leq 16^{\circ} \mathrm{C}$ and $90^{\circ} \mathrm{C} \leq T_{g} \leq 100^{\circ} \mathrm{C}$.

The combined results for R141b [5] and R245fa [16,17] have been used to derive correlations of the loss coefficients that can be used for comparable dry and isentropic refrigerants with reasonable accuracy. The combined loss coefficient in Eqn. (6) is given by

$$
\phi_{p}=1.139+0.01768 \frac{A_{3}}{A_{t}}-0.009797\left(\frac{P_{g}}{P_{e}}\right)-1.08 \tilde{R}
$$

Similarly, the mixing loss coefficient in Eqn. (12) was obtained as

$$
\phi_{m}=0.8264-0.01254 \frac{A_{3}}{A_{t}}+0.005804\left(\frac{P_{g}}{P_{e}}\right)+0.4589 \tilde{R}
$$

The loss coefficient for mixing in the breakdown model was developed using data from Huang et al. [41] and Shestopalov et al. [17] and some additional data from Yen et al. [42] as

$$
\phi_{m p}=0.8802-0.09203 \frac{A_{r}}{A_{r t}}+0.00158\left(\frac{P_{g}}{P_{e}}\right)^{k}
$$

The non-dimensionalized gas constant used in Eqns. (44) and (45), $\tilde{R}$ is the ratio of the refrigerant's gas constant to that of air. Eqns. (44) to (46) are valid for $6.44 \leq A_{r} \leq 12.89,8^{\circ} \mathrm{C} \leq T_{e}$ $\leq 16^{\circ} \mathrm{C}$ and $78^{\circ} \mathrm{C} \leq T_{g} \leq 100^{\circ} \mathrm{C}$.

\subsubsection{Coefficient of performance}

The coefficient of performance (COP) of the ejector refrigeration system is defined as

$$
C O P=\frac{\dot{Q}_{e}}{\dot{Q}_{g}+\dot{W}_{p}}
$$

Where the cooling capacity is

$$
\dot{Q}_{e}=\dot{m}_{s}\left(h_{e o}-h_{e i}\right)
$$

With $h_{e o}$ and $h_{e i}$, the exit and inlet enthalpies for the evaporator evaluated using Engineering Equation Solver (EES) software [43]. The heat transfer rate to the generator is

$$
\dot{Q}_{g}=\dot{m}_{p}\left(h_{g o}-h_{g i}\right)
$$


With $h_{g o}$ and $h_{g i}$, the exit and inlet enthalpies for the generator are also evaluated using EES [43]. The work of the pump is given by

$$
\dot{W}_{p}=\dot{m}_{p}\left(h_{g i}-h_{c o}\right)
$$

Where $h_{c o}$ is the enthalpy at the condenser exit. Combining Eqns. (48)-(50) gives

$$
C O P=\mu \frac{\left(h_{e o}-h_{e i}\right)}{\left(h_{g o}-h_{c o}\right)}
$$

In Eqn. (51), $\mu$ will either be $\mu_{c c}$ according to Eqn. (23) or $\mu_{c i}$ given by Eqn. (37) depending on the mode of operation. At the exit of the generator and the evaporator, the vapor is taken to be saturated. After condensation, the liquid enters the evaporator as a saturated liquid while the liquid entering the vapor generator is a compressed liquid. The properties are determined accordingly at these states using built-in property functions in EES [43].

\subsection{Working fluid properties}

The properties of commonly used refrigerants in ejector refrigeration systems and the ones suggested for use in this study are shown in Table 2. The thermodynamic properties of the considered working fluids were obtained directly from EES [43]. The safety and toxicity classification, the GWP and the ODP of the different refrigerants were obtained from the respective references indicated in Table 2. As the table shows, R141b and R123 are in the class of refrigerants that are banned owing to ODP values greater than zero, whereas R134a and R245fa will soon be phased out as they possess GWP values much higher than 150 [24].

Figure 4 shows the $T$-s diagram for different refrigerants. The $T$-s diagram for each refrigerant was

plotted using data extracted from EES [43] based on the ASHRAE reference state. From the $T-s$ diagrams it is easier to determine which refrigerants are considered as wet (negative slope of the saturated vapor line), isentropic (vertical saturated vapor line) or dry (positive slope of the saturated vapor line).

In this study, HFO refrigerants with very low GWP and no ODP i.e. R1336mzz(Z) also referred to as HFO1336mzz(Z), R1233zd(E), R1234ze(Z), RE245fa2 and R600 have been considered as replacements of the conventional refrigerants in the ejector refrigeration system. Most of the considered environmentally benign refrigerants except $\mathrm{R} 600$ and $\mathrm{R} 1336 \mathrm{mzz}(\mathrm{Z})$ have almost the same shape of the temperature-entropy diagram as R141b and R245fa. As depicted in Fig. 4, the considered refrigerants are either dry or isentropic working fluids. Dry and isentropic working 
fluids were considered in this study: firstly, to ensure that the Huang et al. [5] model can be applied with reasonable accuracy, and secondly because it has been shown that dry refrigerants give higher values of the entrainment ratio compared to wet refrigerants [22]. Moreover, with dry working fluids, the possibility of having liquid droplets during expansion in the nozzle is eliminated and thus there is no need to superheat the fluid entering the ejector. With no condensation in the nozzle there are less friction losses and therefore improved performance. It should be noted that the alternative refrigerants considered are newly introduced refrigerants of the HFO family. This study aims to contribute to the understanding of how these refrigerants perform in an ejector refrigeration system compared to R141b and R245fa.

Table 2. Working fluid properties

\begin{tabular}{lllllllll}
\hline Refrigerant & $\begin{array}{l}\text { Molecular } \\
\text { Mass } \\
(\mathbf{k g} / \mathbf{k m o l})\end{array}$ & $\begin{array}{l}\text { Boling } \\
\text { point } \\
\left({ }^{\circ} \mathbf{C}\right)\end{array}$ & $\begin{array}{l}\text { Critical } \\
\text { Temperature } \\
\left({ }^{\circ} \mathbf{C}\right)\end{array}$ & $\begin{array}{l}\text { Critical } \\
\text { Pressure } \\
(\mathbf{M P a})\end{array}$ & $\begin{array}{l}\text { Fluid type } \\
\text { (wet/dry) }\end{array}$ & $\begin{array}{l}\text { Safety } \\
\text { group }\end{array}$ & ODP & GWP \\
\hline R141b & 116.95 & 32.1 & 204.4 & 4.21 & dry & A2 & $0.11[44]$ & $725[44]$ \\
R245fa & 134.05 & 15.1 & 154.0 & 3.65 & dry & B1 & None[34,37] & $1050[34,37]$ \\
R1336mzz(Z) & 164.10 & 33.4 & 171.3 & 2.90 & dry & A1 ${ }^{*}$ & None[34] & $2[34]$ \\
R123 & 152.90 & 27.9 & 184.0 & 3.70 & dry & B1 & $0.02-0.06[44]$ & $77[44]$ \\
R134a & 102.03 & -26.0 & 101.0 & 4.10 & wet & A1 & None & $1430[45]$ \\
R1233zd(E) & 131.00 & 19.0 & 166.0 & 3.60 & dry & A1<A2L & None & $4.5[46]$ \\
RE245fa2 & 150.00 & 29.24 & 171.7 & 3.43 & dry & & None & $286[45]$ \\
R600 & 58.12 & -0.53 & 152.0 & 3.80 & isentropic & A3 & None & $4[45]$ \\
R600a & 58.12 & -11.68 & 134.7 & 3.64 & isentropic & A3 & None & $4[45]$ \\
R290 & 44.1 & -42.1 & 96.68 & 4.25 & wet & A3 & None & $3[45]$ \\
R1234ze(Z) & 114 & 9.28 & 150.1 & 3.53 & wet & A1<A2L & None & $6[45]$ \\
R1234ze(E) & 114 & -19.28 & 109.4 & 3.63 & isentropic & A1<A2L & None & $6[45]$ \\
R365mfc & 148.1 & 40.18 & 186.9 & 3.27 & dry & & None & 1110 \\
\hline
\end{tabular}




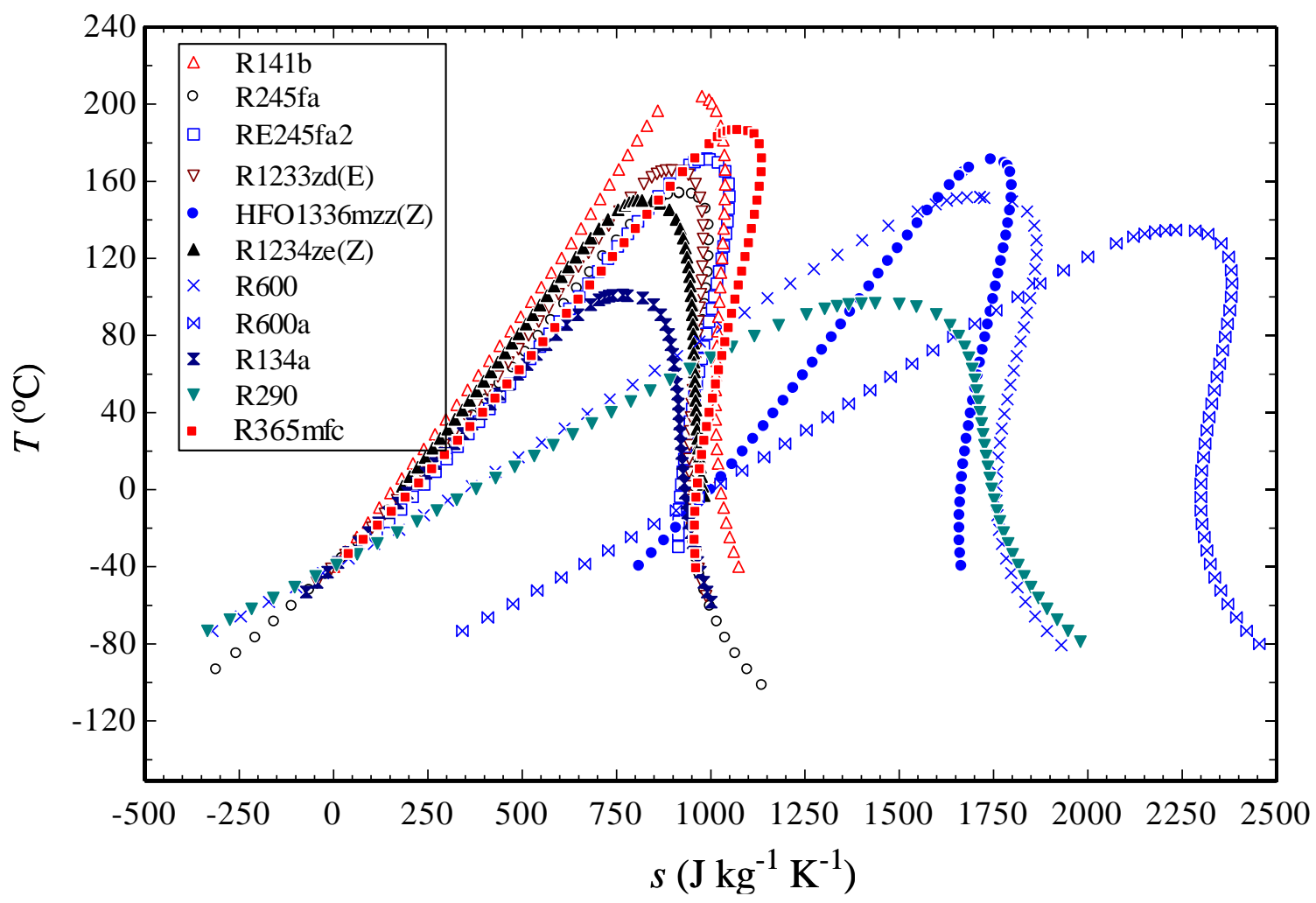

Fig. 4. T-s diagrams for different refrigerants (data obtained from EES with the ASHRAE reference state)

\subsection{Solution methodology}

The solution of the ejector model Eqns. (1) to (37), together with the equations of the developed model coefficients, (38) to (46) and the equations for the COP, (47) to (51) was obtained iteratively using a program written in EES [43]. Unlike other programs written previously that use manual iterative procedures, EES uses an internal iterative solver which blocks the equations that can be solved together in the same groups. The solution procedure is depicted in the flow chart shown in Fig. 5. The ejector throat diameter $\left(d_{t}\right)$, the ejector nozzle exit diameter $\left(d_{1}\right)$, and the ejector constant area section diameter $\left(d_{3}\right)$ for a given ejector as specified in Table 3 are specified and the respective areas determined. The other main parameters that must be supplied to fully characterize the performance of the ejector are the ejector primary flow inlet temperature $\left(T_{g}\right)$, and the ejector secondary flow inlet temperature $\left(T_{e}\right)$. The total pressure of the primary flow at the ejector inlet $\left(P_{g}\right)$ is obtained from the specified value of $T_{g}$ at the saturated conditions. Similarly, the total pressure of the secondary flow at the ejector inlet $\left(P_{e}\right)$ is obtained from $T_{e}$. 


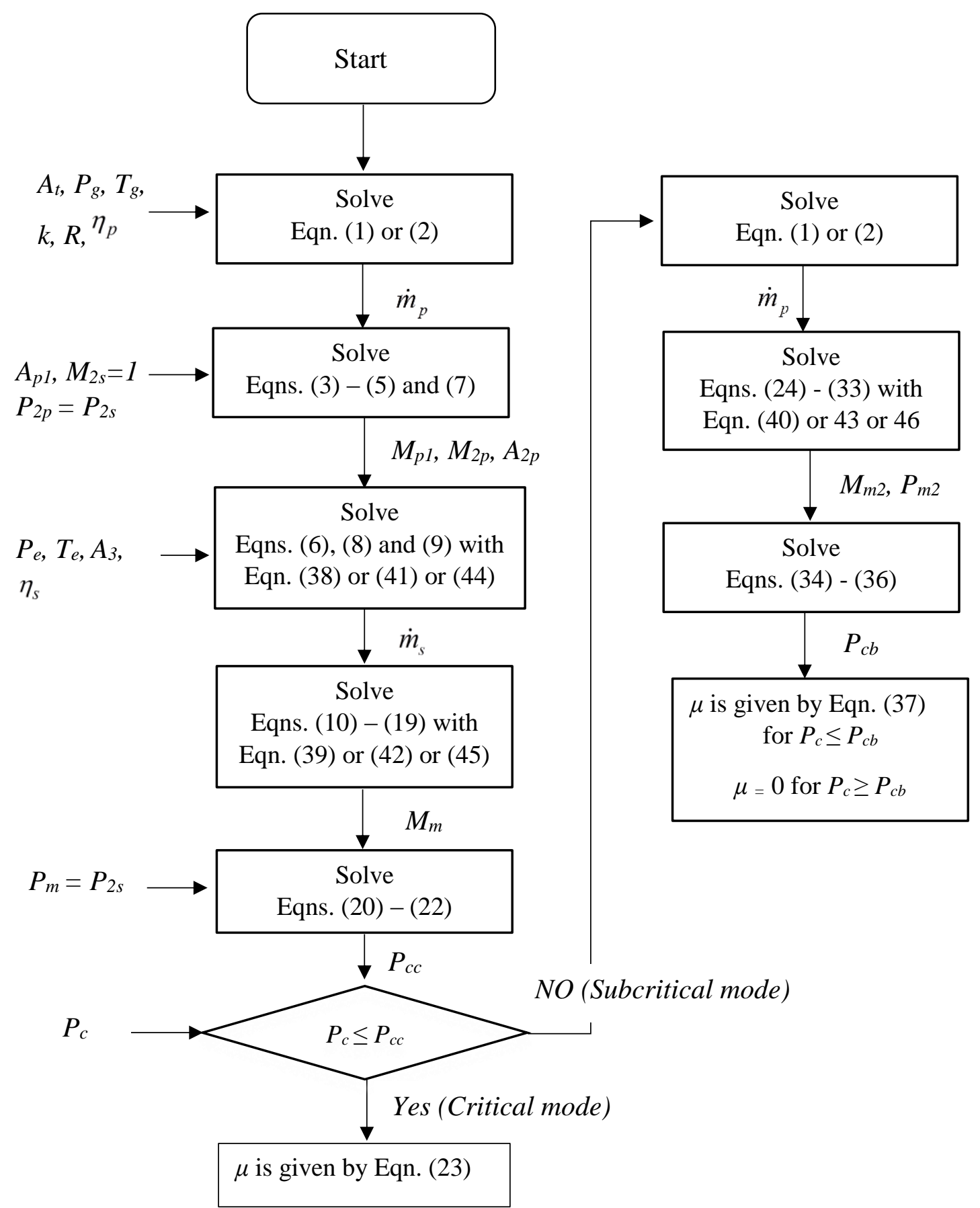

Fig. 5. Flow chart showing the solution methodology used in analysis of ejector performance Solving Eqns. (1)-(23), the specified condensing pressure $\left(P_{c}\right)$ is compared with the evaluated critical condensing pressure $\left(P_{c c}\right)$. If $P_{c}$ is found to be less than $P_{c c}$, the obtained value of the entrainment ratio is the critical entrainment ratio $\left(\mu_{c c}\right)$ and all the parameters evaluated at this point correspond to the critical mode of operation. If $P_{c}$ is found to be greater than $P_{c c}$ but lower than the 
breakdown pressure $\left(P_{c b}\right)$, the ejector is operating in the subcritical mode and the value of the entrainment ratio $\mu_{c i}$ is less than $\mu_{c c}$ but greater than zero. The entrainment ratio, $\mu_{c i}$ is then obtained using Eqn. (37) after solving Eqns. (24)-(36) and (23). At the point where the entrainment ratio is zero, the temperature corresponds to breakdown temperature. Due to the limited data used for the breakdown model, there are cases where $P_{c b}$ is less than $P_{c c}$, mostly for the combined model this is not physically possible. In such cases, the value of $\phi_{m p}$ is selected such that $T_{c b}$ is about $3^{\circ} \mathrm{C}$ above $T_{c c}$.

The coefficients accounting for nozzle losses for both the primary flow and the secondary flow have been shown to be constant and have been taken as $\eta_{p}=0.95$ and $\eta_{s}=0.85[5,18,21]$. The other coefficients were evaluated using the developed models. For a converged solution, conservative relative residuals of $10^{-7}$ and a strict change in variables after each iteration of $10^{-10}$ were used. In all cases 250 iterations were enough to ensure a converged solution.

During the preliminary analysis using R141b, a range of ejector geometries as shown in Table 3 were considered. For further analysis and optimization of the ejector with different refrigerants, ejector geometries were selected with area ratios in the range of the studies by Huang et al. [5] and Shestopalov et al. [17]. The area ratios considered in the analysis were $4.45 \leq A_{r} \leq 12.76$. The geometries selected to give these area ratios were: ejector AA from Huang et al. [5], ejectors 1-A, and 2-B from Shestopalov et al. [17] and three other geometries put together in this study (1_1, 3_1 and 5_2) as shown in Table 3. The key dimensions of the ejectors considered are also shown in Table 3.

Table 3: Ejector geometries

\begin{tabular}{lcrrr}
\hline Ejector & $d_{t}(\mathrm{~mm})$ & $d_{l}(\mathrm{~mm})$ & $d_{3}(\mathrm{~mm})$ & $A_{r}[-]$ \\
\hline AA[5] & 2.64 & 4.5 & 6.7 & 6.44 \\
AD[5] & 2.64 & 4.5 & 8.1 & 9.41 \\
EF[5] & 2.82 & 5.1 & 8.84 & 9.83 \\
1-A[16] & 4.515 & 7.8 & 12.155 & 7.25 \\
2-B[16] & 4.212 & 7.11 & 13.01 & 9.54 \\
3-C[16] & 3.902 & 6.412 & 14.01 & 12.89 \\
1_1 & 2.75 & 4.5 & 5.8 & 4.45 \\
2_1 & 2.25 & 4.5 & 5.8 & 6.64 \\
3_1 & 1.75 & 4.5 & 5.8 & 10.98 \\
4_2 & 3.25 & 6.5 & 12.5 & 14.79 \\
5_2 & 3.5 & 6.5 & 12.5 & 12.76 \\
\hline
\end{tabular}




\begin{tabular}{lcccc}
\hline $6 \_2$ & 4.00 & 6.5 & 12.5 & 9.77 \\
$7 \_2$ & 4.5 & 6.5 & 12.5 & 7.72 \\
\hline
\end{tabular}

\subsection{Validation of the developed models}

The widely used experimental and theoretical data provided in a study by Huang et al. [5] for different ejector geometries and with R141b as the refrigerant were used to validate the present model. Table 4(a) shows the comparison of the present study results with the results from Huang et al. [5] and with results from the model developed by Li et al. [21]. About 92\% of the critical entrainment ratio values are predicted within $\pm 5.5 \%$ of the experimental values obtained in Huang et al. [5]. The values of the critical condensing temperatures were in excellent agreement with experimentally obtained values: all within $\pm 0.8^{\circ} \mathrm{C}$ of the values obtained experimentally. As shown, our results give errors significantly lower than those in Huang et al. [5], and comparable to those in Li et al. [21] even though this study and Li et al. [21] use different approaches to model the mixing process in the ejector's constant area section. This study also determines the equations for the loss coefficient simply using non-linear regression while in Li et al. [21], the sparsityenhanced optimization method is used. Despite the different approaches used, the average absolute error in determining the entrainment ratio is $2.75 \%$ in this study which is comparable to $2.66 \%$ in $\mathrm{Li}$ et al. [21]. Moreover, this study performs better than the Li et al. [21] study for 16 of the data points presented in Table 4(a). Thus, the model developed in this study can predict the performance of the ejector using R141b with reasonable accuracy and better than the models using a similar modeling approach presented in previous studies such as Huang et al. [5].

To further validate the ejector model, present study results have also been compared with experimental results from Wang et al. [47] for an ejector with an area ratio, $A_{r}=7.73\left(d_{t}=2.64\right.$ $\mathrm{mm}, d_{p l}=4.5 \mathrm{~mm}$ and $d_{m}=7.34 \mathrm{~mm}$ ). As Table 4(b) shows, the COP obtained in this study is within $\pm 5.6 \%$ of the values in Wang et al. [47] for the range of evaporator temperatures used in in the present work (i.e. $8^{\circ} \mathrm{C} \leq T_{e} \leq 16^{\circ} \mathrm{C}$ ). At an evaporator temperature of $0.35^{\circ} \mathrm{C}$, the percentage error is $7.02 \%$, which is still reasonable compared to the Huang et al. [5] model. Good agreement is also obtained for the cooling capacity giving values within $\pm 5.54 \%$ of the experimental results for all the evaporator temperatures in Table 4(b). 
Table 4(a): Validation of ejector model working R141b with experimental data from Huang et al. [5]

\begin{tabular}{|c|c|c|c|c|c|c|c|c|c|c|c|}
\hline \multirow[b]{2}{*}{ Nozzle } & \multirow[b]{2}{*}{$T_{g}\left({ }^{\circ} \mathrm{C}\right)$} & \multicolumn{4}{|c|}{$T_{c c}\left({ }^{\circ} \mathrm{C}\right)$} & \multicolumn{3}{|c|}{ Entrainment ratio, $(\mu)$} & \multicolumn{3}{|c|}{$\begin{array}{l}\text { Percentage error in } \mu \text { (Theoretical } \\
\text { compared with experimental) }\end{array}$} \\
\hline & & $T_{e}\left({ }^{\mathrm{o}} \mathrm{C}\right)$ & $\begin{array}{c}\text { (Exp) } \\
\text { Huang } \\
\text { et al. } \\
\text { [5] }\end{array}$ & $\begin{array}{l}\text { Present } \\
\text { study }\end{array}$ & $\begin{array}{c}\mu_{c c} \\
(\operatorname{Exp}) \\
\text { Huang et } \\
\text { al. [5] }\end{array}$ & $\begin{array}{c}\mu_{c c} \\
\text { (Theory) } \\
\text { Huang } \\
\text { et al. [5] }\end{array}$ & $\begin{array}{c}\mu_{c c} \\
\text { Li et al. } \\
{[21]}\end{array}$ & $\begin{array}{c}\mu_{c c} \\
\text { Present } \\
\text { study }\end{array}$ & $\begin{array}{c}\text { Error, \% } \\
\text { Huang et } \\
\text { al. [5] }\end{array}$ & $\begin{array}{c}\text { Error, \% } \\
\text { Li et al. } \\
{[21]}\end{array}$ & $\begin{array}{c}\text { Error, \% } \\
\text { Present } \\
\text { study }\end{array}$ \\
\hline \multicolumn{12}{|l|}{ AA } \\
\hline \multirow[t]{7}{*}{$A_{r}=6.44$} & 95 & 8 & 42.1 & 41.7 & 0.1859 & 0.1554 & 0.1826 & 0.1803 & -16.41 & -1.78 & -3.01 \\
\hline & 90 & 8 & 38.9 & 38.6 & 0.2246 & 0.2156 & 0.2204 & 0.2183 & -4.01 & -1.87 & -2.80 \\
\hline & 84 & 8 & 35.5 & 35.2 & 0.2880 & 0.2880 & 0.2760 & 0.2748 & 0.23 & -4.17 & -4.58 \\
\hline & 78 & 8 & 32.5 & 31.7 & 0.3257 & 0.3525 & 0.3440 & 0.3454 & 8.23 & 5.62 & 6.05 \\
\hline & 95 & 12 & 42.5 & 42.5 & 0.2350 & 0.2573 & 0.2373 & 0.2396 & 9.49 & 0.98 & 1.96 \\
\hline & 90 & 12 & 39.5 & 39.6 & 0.2946 & 0.3257 & 0.2831 & 0.2871 & 10.56 & -3.90 & -2.55 \\
\hline & 84 & 12 & 36.0 & 36.1 & 0.3390 & 0.4147 & 0.3500 & 0.3566 & 22.33 & 3.24 & 5.19 \\
\hline \multicolumn{12}{|l|}{$\mathrm{AB}$} \\
\hline \multirow[t]{3}{*}{$A_{r}=6.99$} & 90 & 8 & 37.5 & 37.2 & 0.2718 & 0.2093 & 0.2577 & 0.257 & -22.99 & -5.19 & -5.45 \\
\hline & 84 & 8 & 33.6 & 33.6 & 0.3117 & 0.3042 & 0.3197 & 0.3196 & -2.41 & 2.57 & 2.53 \\
\hline & 78 & 8 & 29.5 & 30.2 & 0.3922 & 0.4422 & 0.3952 & 0.3977 & 12.75 & 0.76 & 1.40 \\
\hline \multicolumn{12}{|l|}{$\mathrm{AG}$} \\
\hline \multirow[t]{8}{*}{$A_{r}=7.73$} & 95 & 8 & 38.6 & 38.1 & 0.2552 & 0.2144 & 0.2604 & 0.2606 & -15.99 & 2.04 & 2.12 \\
\hline & 90 & 8 & 36.7 & 35.1 & 0.3040 & 0.2395 & 0.3087 & 0.309 & -21.22 & 1.55 & 1.64 \\
\hline & 84 & 8 & 32.3 & 31.7 & 0.3883 & 0.3704 & 0.3793 & 0.38 & -4.61 & -2.32 & -2.14 \\
\hline & 78 & 8 & 29.1 & 28.3 & 0.4609 & 0.4393 & 0.4648 & 0.4681 & -4.69 & 0.85 & 1.56 \\
\hline & 95 & 12 & 38.7 & 38.9 & 0.3503 & 0.3434 & 0.3304 & 0.3356 & -1.97 & -5.68 & -4.20 \\
\hline & 90 & 12 & 36.0 & 36.0 & 0.4034 & 0.4142 & 0.3883 & 0.3952 & 2.68 & -3.74 & -2.03 \\
\hline & 84 & 12 & 32.4 & 32.6 & 0.4790 & 0.4769 & 0.4724 & 0.4819 & -0.44 & -1.38 & 0.61 \\
\hline & 78 & 12 & 29.2 & 29.4 & 0.6132 & 0.6659 & 0.5737 & 0.5884 & 8.59 & -6.44 & -4.04 \\
\hline \multicolumn{12}{|l|}{$\mathrm{AC}$} \\
\hline \multirow[t]{4}{*}{$A_{r}=8.29$} & 95 & 8 & 36.3 & 36.6 & 0.2814 & 0.2983 & 0.2944 & 0.2953 & 6.01 & 4.62 & 4.94 \\
\hline & 90 & 8 & 33.8 & 33.7 & 0.3472 & 0.3552 & 0.3488 & 0.3482 & 2.30 & 0.46 & 0.29 \\
\hline & 84 & 8 & 30.5 & 30.3 & 0.4241 & 0.4605 & 0.4241 & 0.4255 & 8.58 & 0.00 & 0.33 \\
\hline & 78 & 8 & 26.9 & 27.0 & 0.4889 & 0.5966 & 0.5170 & 0.5212 & 22.03 & 5.75 & 6.61 \\
\hline \multicolumn{12}{|l|}{$\mathrm{AD}$} \\
\hline \multirow[t]{8}{*}{$A_{r}=9.41$} & 95 & 8 & 33.6 & 33.9 & 0.3457 & 0.3476 & 0.3654 & 0.3655 & 0.55 & 5.70 & 5.73 \\
\hline & 90 & 8 & 31.5 & 31.1 & 0.4446 & 0.4178 & 0.4273 & 0.4274 & -6.03 & -3.89 & -3.87 \\
\hline & 84 & 8 & 28.0 & 27.7 & 0.5387 & 0.5215 & 0.5170 & 0.5175 & -3.19 & -4.03 & -3.94 \\
\hline & 78 & 8 & 24.4 & 24.5 & 0.6250 & 0.6944 & 0.6227 & 0.6284 & 11.10 & -0.37 & 0.54 \\
\hline & 95 & 12 & 34.5 & 34.6 & 0.4541 & 0.4708 & 0.4549 & 0.4608 & 3.68 & 0.18 & 1.48 \\
\hline & 90 & 12 & 32.0 & 31.9 & 0.5422 & 0.5573 & 0.5284 & 0.5364 & 2.78 & -2.55 & -1.07 \\
\hline & 84 & 12 & 28.9 & 28.7 & 0.6350 & 0.6906 & 0.6345 & 0.6454 & 8.76 & -0.08 & 1.64 \\
\hline & 78 & 12 & 25.7 & 25.7 & 0.7412 & 0.8626 & 0.7617 & 0.7788 & 16.38 & 2.77 & 5.07 \\
\hline
\end{tabular}


EG

\begin{tabular}{ccccccccccccc}
$A_{r}=6.77$ & 95 & 8 & 41.0 & 40.7 & 0.2043 & 0.1919 & 0.2022 & 0.2011 & -6.07 & -1.03 & -1.57 \\
$\quad$ EC & & & & & & & & & & & & \\
$A_{r}=7.26$ & 95 & 8 & 38.8 & 39.3 & 0.2273 & 0.2078 & 0.2317 & 0.231 & -8.58 & 1.94 & 1.63 \\
& 95 & 12 & 39.3 & 40.1 & 0.3040 & 0.3235 & 0.2961 & 0.3005 & 6.41 & -2.60 & -1.15 \\
$\quad$ ED & & & & & & & & & & & & \\
$A_{r}=8.25$ & 95 & 8 & 37.1 & 36.7 & 0.2902 & 0.2658 & 0.2926 & 0.293 & -8.41 & 0.83 & 0.96 \\
$\quad$ EE & & & & & & & & & & & \\
$A_{r}=9.17$ & 95 & 8 & 34.2 & 34.5 & 0.3505 & 0.3253 & 0.3502 & 0.3504 & -7.19 & -0.09 & -0.03 \\
& 95 & 12 & 34.2 & 35.2 & 0.4048 & 0.4894 & 0.4370 & 0.4428 & 20.90 & 7.95 & 9.39 \\
EF & & & & & & & & & & & \\
$A_{r}=9.83$ & 95 & 8 & 33.0 & 32.9 & 0.3937 & 0.3774 & 0.3921 & 0.3913 & -4.14 & -0.41 & -0.61 \\
EH & 95 & 12 & 33.1 & 33.7 & 0.4989 & 0.5482 & 0.4865 & 0.4916 & 9.88 & -2.49 & -1.46 \\
$A_{r}=10.64$ & 95 & 8 & 31.3 & 31.1 & 0.4377 & 0.4627 & 0.4439 & 0.4422 & 5.71 & 1.42 & 1.03 \\
\hline
\end{tabular}

Table 4(b). Comparison of the R141b ejector model results with Wang et al.[47]

\begin{tabular}{llllllll}
\hline \multicolumn{3}{c}{ COP } & \multicolumn{5}{c}{$\begin{array}{c}\text { Cooling Capacity } \\
\dot{Q}_{e}(\mathrm{~kW})\end{array}$} \\
\hline$T_{e}\left({ }^{\circ} \mathrm{C}\right)$ & Wang et al. [47] & Present study & Error, \% & $T_{e}\left({ }^{\circ} \mathrm{C}\right)$ & Wang et al. [47] & Present study & Error, \% \\
\hline 0.35 & 0.1280 & 0.1345 & 7.02 & 0.33 & 0.437 & 0.413 & -5.54 \\
8.52 & 0.2315 & 0.2416 & 4.37 & 8.25 & 0.760 & 0.727 & -4.30 \\
10.25 & 0.2587 & 0.2676 & 3.42 & 10.21 & 0.836 & 0.824 & -1.49 \\
11.17 & 0.2724 & 0.2860 & 5.01 & 11.13 & 0.883 & 0.873 & -1.08 \\
12.30 & 0.2833 & 0.2990 & 5.57 & 12.27 & 0.929 & 0.937 & 0.91 \\
\hline
\end{tabular}

Furthermore, for R245fa as the working fluid, the results from the developed model have been compared with the results in a study by Shestopalov et al. [17]. In addition to the critical entrainment ratio, the COP as well as the cooling capacity at the critical point have been compared with the values obtained experimentally by Shestopalov et al.[17]. As shown in Table 5, the present study results are in good agreement with the experimental data, giving errors within $\pm 5.34 \%$ for the entrainment ratio, within $\pm 4.84 \%$ for the cooling capacity and within $\pm 4.53 \%$ for the COP. This further shows that the developed model can be used to predict the performance of an ejector system with acceptable accuracy. 
Table 5: Validation of ejector model working R245fa with experimental data from Shestopalov et al. [17]

\begin{tabular}{|c|c|c|c|c|c|c|c|c|c|c|c|}
\hline \multirow[b]{2}{*}{ Nozzle } & \multirow[b]{2}{*}{$T_{g}\left({ }^{\circ} \mathrm{C}\right)$} & \multirow[b]{2}{*}{$T_{e}\left({ }^{\circ} \mathrm{C}\right)$} & \multicolumn{2}{|l|}{$\mu_{c c}$} & \multicolumn{4}{|c|}{ Cooling capacity $(\mathrm{kW})$} & \multicolumn{3}{|c|}{$\mathrm{COP}$} \\
\hline & & & $\begin{array}{c}\text { Shestopalov et } \\
\text { al.[17] }\end{array}$ & $\begin{array}{c}\text { Present } \\
\text { study }\end{array}$ & $\begin{array}{c}\text { Error, } \\
\%\end{array}$ & $\begin{array}{c}\text { Shestopalov et } \\
\text { al.[17] }\end{array}$ & $\begin{array}{c}\text { Present } \\
\text { study }\end{array}$ & $\begin{array}{c}\text { Error, } \\
\%\end{array}$ & $\begin{array}{c}\text { Shestopalov } \\
\text { et al.[17] }\end{array}$ & $\begin{array}{l}\text { Present } \\
\text { study }\end{array}$ & $\begin{array}{c}\text { Error, } \\
\%\end{array}$ \\
\hline $\begin{array}{c}1-\mathrm{A} \\
\left(A_{r}=7.25\right)\end{array}$ & 90 & 8 & 0.241 & 0.247 & 2.49 & 3.10 & 2.95 & -4.84 & 0.186 & 0.193 & 3.76 \\
\hline $\begin{array}{c}1-\mathrm{B} \\
\left(A_{r}=8.32\right)\end{array}$ & 90 & 8 & 0.318 & 0.325 & 2.04 & 4.10 & 3.94 & -3.98 & 0.243 & 0.236 & -3.05 \\
\hline $\begin{array}{c}1-\mathrm{C} \\
\left(A_{r}=9.63\right)\end{array}$ & 90 & 8 & 0.402 & 0.420 & 4.40 & 5.20 & 5.14 & -1.17 & 0.309 & 0.301 & -2.49 \\
\hline $\begin{array}{c}2-\mathrm{A} \\
\left(A_{r}=8.33\right)\end{array}$ & 95 & 12 & 0.345 & 0.355 & 2.93 & 4.40 & 4.25 & -3.41 & 0.265 & 0.254 & -4.34 \\
\hline $\begin{array}{c}2-\mathrm{B} \\
\left(A_{r}=9.55\right)\end{array}$ & 95 & 12 & 0.423 & 0.442 & 4.54 & 5.40 & 5.29 & -2.04 & 0.323 & 0.318 & -1.55 \\
\hline $\begin{array}{c}2-\mathrm{C} \\
\left(A_{r}=11.06\right)\end{array}$ & 95 & 12 & 0.536 & 0.563 & 4.96 & 7.00 & 6.83 & -2.37 & 0.411 & 0.403 & -1.90 \\
\hline $\begin{array}{c}3-\mathrm{A} \\
\left(A_{r}=9.71\right)\end{array}$ & 100 & 16 & 0.471 & 0.493 & 4.71 & 5.70 & 5.58 & -2.11 & 0.358 & 0.349 & -2.60 \\
\hline $\begin{array}{c}3-\mathrm{B} \\
\left(A_{r}=11.14\right)\end{array}$ & 100 & 16 & 0.575 & 0.600 & 4.38 & 7.00 & 6.96 & -0.51 & 0.440 & 0.429 & -2.43 \\
\hline $\begin{array}{c}3 \mathrm{C} \\
\left(A_{r}=12.89\right)\end{array}$ & 100 & 16 & 0.744 & 0.743 & -0.16 & 9.20 & 9.14 & -0.63 & 0.570 & 0.554 & -2.86 \\
\hline $\begin{array}{c}2 \mathrm{~B} \\
\left(A_{r}=9.55\right)\end{array}$ & 95 & 8 & 0.328 & 0.346 & 5.34 & 4.00 & 4.05 & 1.15 & 0.245 & 0.242 & -1.35 \\
\hline $\begin{array}{c}2 \mathrm{~B} \\
\left(A_{r}=9.55\right)\end{array}$ & 95 & 12 & 0.425 & 0.446 & 4.87 & 5.40 & 5.25 & -2.80 & 0.342 & 0.326 & -4.59 \\
\hline $\begin{array}{c}2 \mathrm{~B} \\
\left(A_{r}=9.55\right)\end{array}$ & 95 & 16 & 0.550 & 0.564 & 2.62 & 7.00 & 6.85 & -2.20 & 0.435 & 0.415 & -4.53 \\
\hline
\end{tabular}

With the model using combined data for R141b and R245fa, the performance of the ejector system using all the data in Table 4(a) was predicted within $\pm 7 \%$ of the experimental values except for 3 of the 39 data points which had values above $7 \%$. These data points had errors of $8.28 \%$ (ejector AC with $T_{e}=8^{\circ} \mathrm{C}$ and $T_{g}=78^{\circ} \mathrm{C}$ ), $8.56 \%$ (ejector AD with $T_{e}=8^{\circ} \mathrm{C}$ and $T_{g}=95^{\circ} \mathrm{C}$ ) and $12.18 \%$ (ejector EE with $T_{e}=12^{\circ} \mathrm{C}$ and $T_{g}=95^{\circ} \mathrm{C}$ ). These are the same configurations with the highest errors in the ejector model for R141b alone. This might be due to the high experimental uncertainties at these specific data points. However, these values are significantly lower than the errors in previous studies including Huang et al. [5]. The model predicts all results within $\pm 6.5 \%$ except two of the R245fa ejectors in Shestopalov et al. [17]. For the two ejectors, 1-A and 2-B, the errors were $10 \%$ and $10.7 \%$, respectively. 
The combined model developed in this work can be used to investigate the performance of an ejector refrigeration system working with refrigerants similar to R141b and R245fa with acceptable accuracy. For consistency with the refrigerants with which the model coefficients were obtained, the refrigerants in this work have been limited to mostly dry and isentropic refrigerants with the values of the compressibility factor close to those of R141b and R245fa for the range of operation considered in this study. The refrigerants considered include $\mathrm{R} 1336 \mathrm{mzz}(\mathrm{Z})$ also referred to as HFO1336mzz(Z), R1233zd(E), R1234ze(Z), RE245fa2, and R600. R1234ze(Z) can be considered approximately isentropic for the range of temperatures and pressures considered in this study.

There are limited experimental studies on the use of HFOs and other alternative refrigerants in ejector refrigeration systems. As such, data for validation of the combined model using dry/isentropic refrigerants other than R141b and R245fa refrigerants is rare in the literature. The combined model has been derived using R141b and R245fa (with compressibility factors of 0.88 and 0.79 at $90^{\circ} \mathrm{C}$ and 0.98 and 0.96 at $8^{\circ} \mathrm{C}$, respectively - all obtained at the saturated vapor states). The compressibility factor shows how well the ideal gas model is approached, with a compressibility factor of 1 indicating an ideal gas. Therefore, the model is expected to give reasonably accurate results for dry and isentropic refrigerants with compressibility factors close to or above the ones of R141b and R245fa. The compressibility factors of considered refrigerants, HFO1336mzz(Z), R1233zd(E), R1234ze(Z), RE245fa2, and R600 at $90^{\circ} \mathrm{C}$ at saturated vapor conditions are $0.85,0.81,0.76,0.78$ and 0.76 , respectively. The respective compressibility factors at $8^{\circ} \mathrm{C}$ are $0.99,0.96,0.97,0.82$ and 0.95 .

The combined model has been verified using results of R365mfc available in the literature [47]. The R365mfc saturated vapor has compressibility factors of 0.87 and 0.98 at $90^{\circ} \mathrm{C}$ and $8^{\circ} \mathrm{C}$, respectively. As Table 6 shows, the model developed in the study predicts ejector performance reasonably well, provided that the evaporator temperature is between 8 and $16^{\circ} \mathrm{C}$ and the area ratios and other parameters are within the range considered in deriving the model. The COP is within $\pm 11 \%$ and the cooling capacity is within $\pm 9 \%$ of the experimental values by Wang et al. [47]. This validation shows that the combined model can predict ejector performance with acceptable accuracy for dry and isentropic working fluids with compressibility factors comparable to R141b and R245fa, the two working fluids used to derive the model. Since there are no ejector models for other refrigerants except R141b, R245fa and R134a, the combined model developed in 
this study gives a preliminary means of comparing ejector performance with different dry and isentropic working fluids while accounting for the variation of ejector loss coefficients with generator and evaporator temperatures as well as the ejector area ratio.

Table 6: Validation of the combined model using experimental data for R365mfc[47].

\begin{tabular}{|c|c|c|c|c|c|c|c|}
\hline \multicolumn{8}{|c|}{$T_{g}=90^{\circ} \mathrm{C}, A_{r}=7.73$} \\
\hline & \multirow{2}{*}{\multicolumn{3}{|c|}{$\mathrm{COP}$}} & \multicolumn{4}{|c|}{ Cooling Capacity } \\
\hline & & & & \multicolumn{4}{|c|}{$\dot{Q}_{e}(\mathrm{~kW})$} \\
\hline$T_{e}\left({ }^{\circ} \mathrm{C}\right)$ & $\begin{array}{r}\text { Wang et al. } \\
\text { [47] }\end{array}$ & $\begin{array}{r}\text { Present } \\
\text { study }\end{array}$ & Error, \% & $T_{e}\left({ }^{\circ} \mathrm{C}\right)$ & $\begin{array}{l}\text { Wang et } \\
\text { al. [47] }\end{array}$ & $\begin{array}{r}\text { Present } \\
\text { study }\end{array}$ & Error, \% \\
\hline 10.58 & 0.1295 & 0.1440 & 10.89 & 10.42 & 0.375 & 0.390 & 4.05 \\
\hline 11.70 & 0.1459 & 0.1609 & 10.31 & 11.80 & 0.436 & 0.430 & -1.45 \\
\hline 16.11 & 0.2197 & 0.2298 & 4.61 & 15.93 & 0.629 & 0.611 & -2.79 \\
\hline 20.72 & 0.2880 & 0.3194 & 10.90 & 20.64 & 0.844 & 0.843 & -0.10 \\
\hline \multicolumn{8}{|c|}{$T_{g}=90^{\circ} \mathrm{C}, A_{r}=9.10$} \\
\hline 9.14 & 0.2197 & 0.1943 & -11.36 & 9.16 & 0.690 & 0.631 & -8.52 \\
\hline 10.99 & 0.2443 & 0.2171 & -11.12 & 10.88 & 0.759 & 0.729 & -3.99 \\
\hline 15.91 & 0.3017 & 0.3110 & 3.09 & 15.70 & 0.959 & 1.024 & 6.75 \\
\hline 18.67 & 0.3372 & 0.3741 & 10.94 & 18.57 & 1.082 & 1.182 & 9.22 \\
\hline
\end{tabular}

Until now, the ability of the developed model to predict the critical condenser temperature and the breakdown temperature has not been shown in the present study. Moreover, most models in the literature do not include the determination of the ejector breakdown temperature. Using the data in Huang et al. [41], the results of the critical condensing temperature and the breakdown temperature in this study are compared with the experimental results. As Fig. 6 shows, the model accurately predicts the critical condensing temperatures and the breakdown temperatures, all within $\pm 0.8^{\circ} \mathrm{C}$. The critical entrainment ratio is also in agreement with the one given in Huang et al. [41] as depicted in Fig. 6, further underpinning the ability of the model to predict ejector performance. 


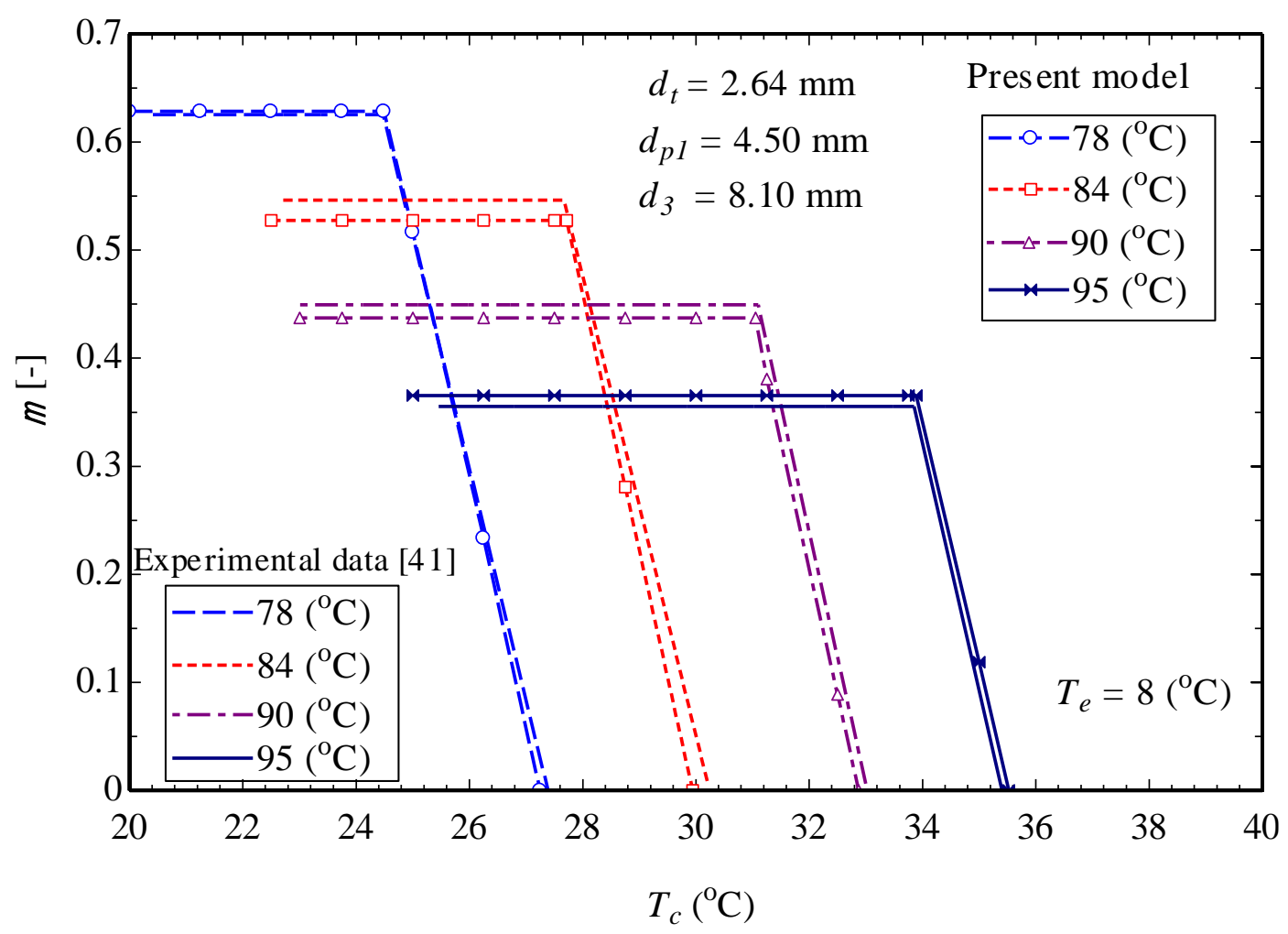

Fig. 6. Comparison of ejector critical temperature and breakdown temperature at different generator temperatures and $T_{e}=8^{\circ} \mathrm{C}$ with R141b [41]

\subsection{Results and discussion}

\subsection{Performance analysis using R141b}

In this section and using the improved model, a detailed analysis of an ejector refrigeration system using R141 as the working fluid has been undertaken. This section seeks to establish ejector performance characteristics under different working conditions before performance with different refrigerants is investigated.

A preliminary investigation on the influence of area ratio on ejector performance was undertaken using all the different ejector geometries in Table 3. As shown in Fig. 7, the ejector critical entrainment ratio increases with rising area ratios. This is due to the increased primary flow rate through the nozzle and the resulting increase in the entrained secondary flow rate owing to an increase in the mixing chamber cross-section area. The increase in the secondary flow rate is more than the increase in the primary flow rate, giving higher entrainment ratios as the area ratio increases. Figure 7 also shows that the critical entrainment ratio decreases with increasing 
generator temperatures at a given area ratio. This is a result of an increase in the vapour pressure as the temperatures increase, leading to higher primary flow mass flow rates. As the primary flow mass flow rate increases, it occupies a larger area of the mixing section, leaving a smaller flow area for the secondary flow. This lowers the mass flow rate of the secondary flow that is entrained, thus a lower entrainment ratio. As the generator temperature increases further at any given area ratio, there is a likelihood of ejector malfunctioning as there is no more area for the secondary flow at the mixing section. In this case, the entrainment ratio becomes zero. This occurs at lower generator temperatures in ejectors with smaller area ratios than those with larger area ratios. For example, for an area ratio of 4.45 in Fig. 7, the entrainment ratio approaches zero just after $110^{\circ} \mathrm{C}$, for other area ratios, this happens at much higher temperatures.

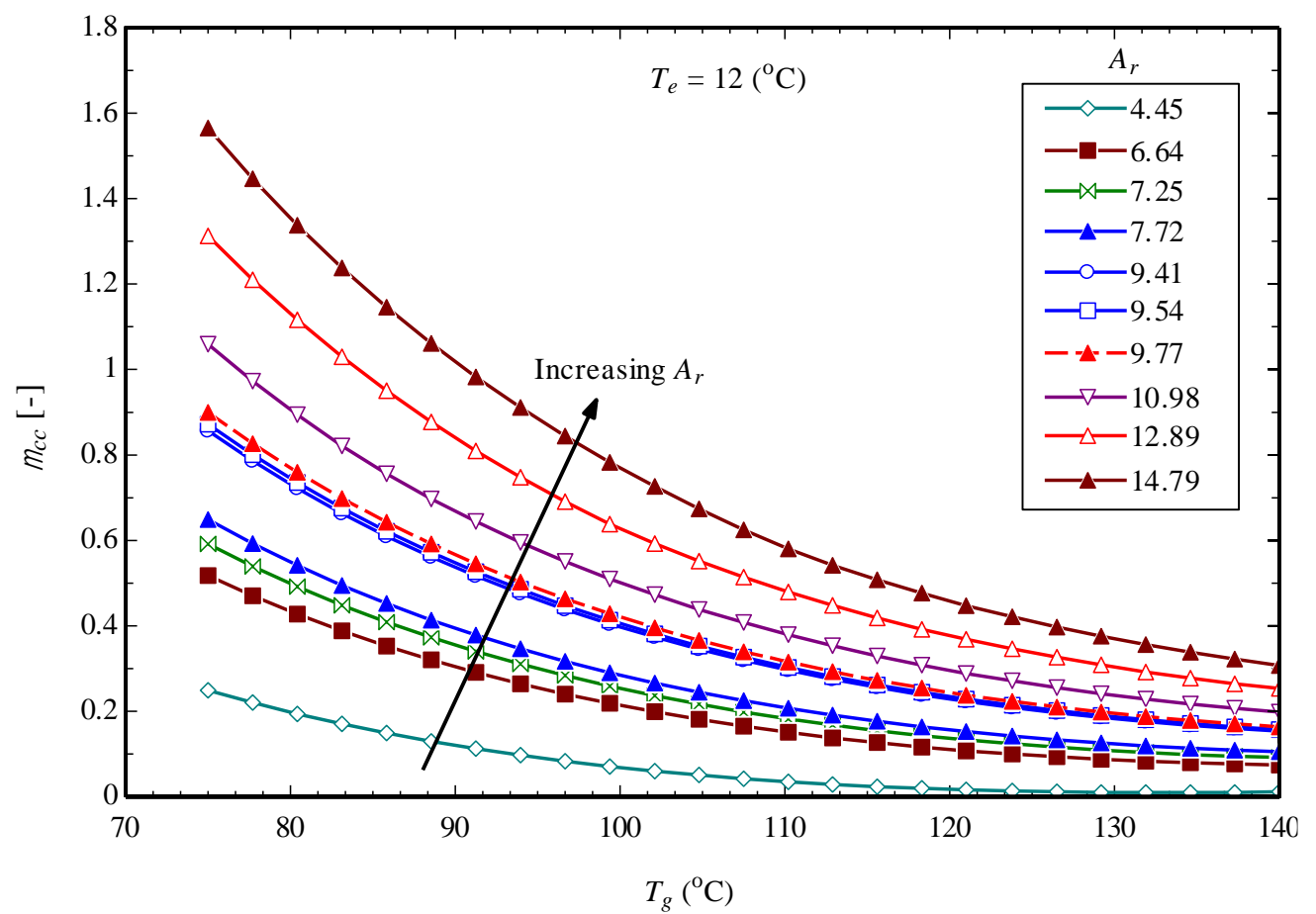

Fig. 7. Critical entrainment ratio as a function of generator temperature at different area ratios with $\mathrm{R} 141 \mathrm{~b}$ and $T_{e}=12^{\circ} \mathrm{C}$

The critical COP follows the same trend as the entrainment ratio as depicted in Fig. 8 for the same reasons discussed earlier. According to Eqn. (51), the entrainment ratio and the COP are directly proportional. Under the critical mode of operation considered in obtaining Figs. (7) and (8), it should be noted both the primary flow and secondary flow are chocked. As such, the condensing temperature/pressure is lower than the critical value and has no influence on ejector performance. 


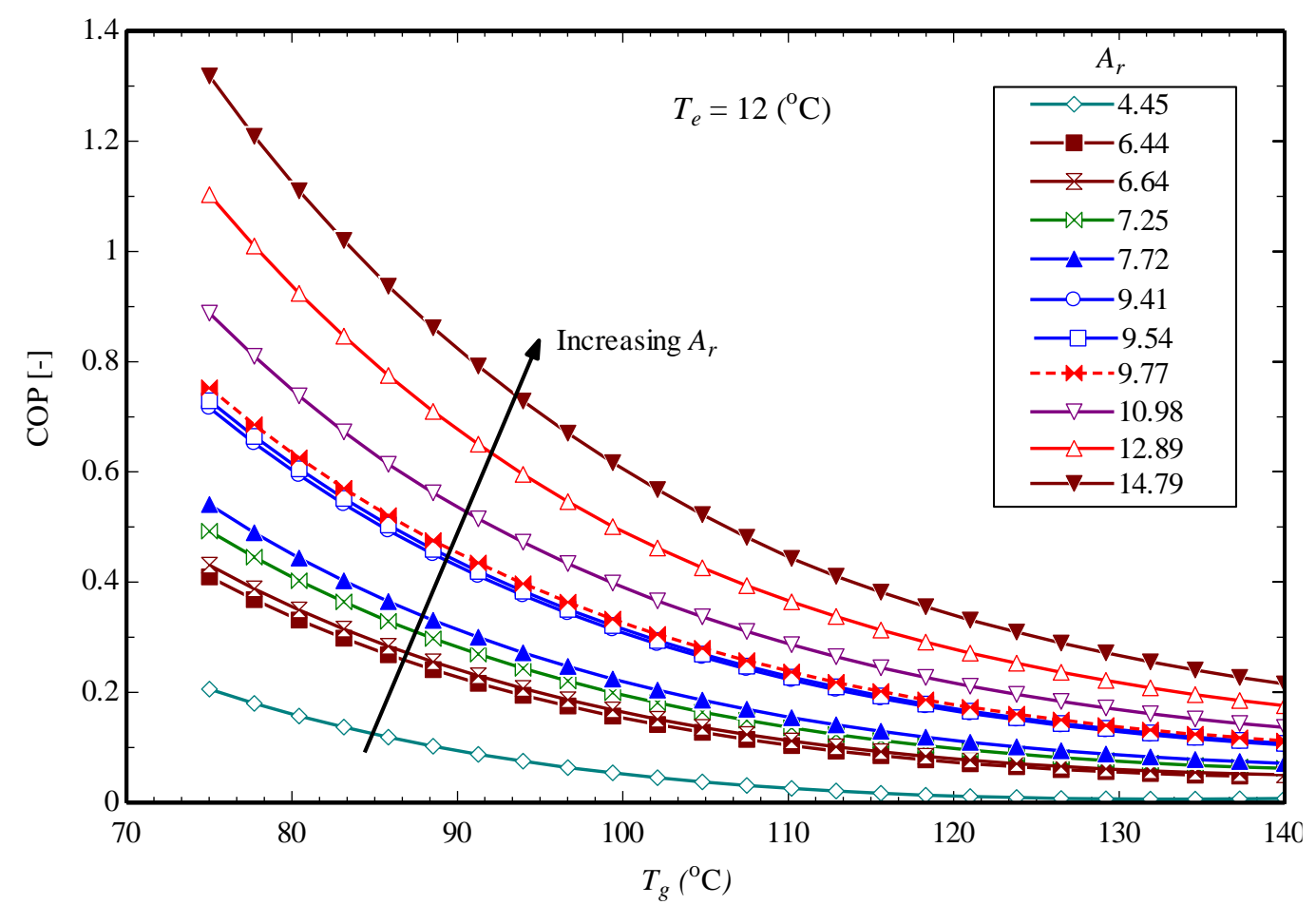

Fig. 8. Critical COP as a function of generator temperature for an ejector using R $141 \mathrm{~b}$ with $T_{e}=$ $12^{\circ} \mathrm{C}$

The critical condensing temperature determines the range of condensing temperatures within which the ejector operates in the critical and desired mode of operation. In Fig. 9, the critical and subcritical modes of operation are distinctly evident at different area ratios with $T_{g}=90^{\circ} \mathrm{C}$ and $T_{e}$ $=12^{\circ} \mathrm{C}$. The portion of the graph where the COP stays constant as the condensing temperature changes indicates that the ejector is working in the critical mode. The portion where the COP reduces as the condensing temperature increases indicates that the ejector operates in the subcritical mode of operation. As the figure shows, the critical condensing temperature decreases with increasing area ratio at a given generator temperature, while at a given area ratio, the critical condensing temperature rises as the generator temperature goes up as shown in Fig. 10. Higher generator temperatures result in higher primary flow rates that keep both the primary flow and secondary flow chocked over a wide range of condensing temperatures. 


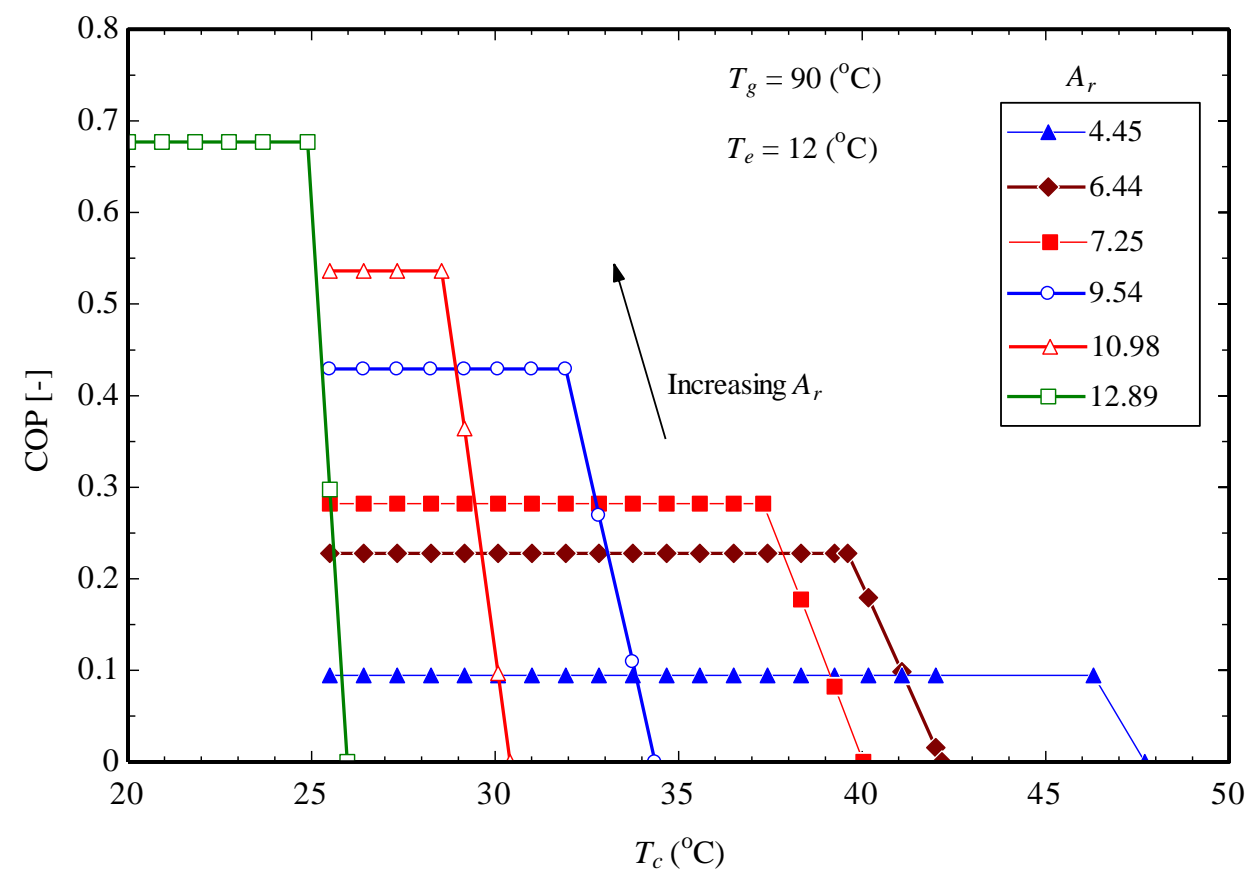

Fig. 9. $\mathrm{COP}$ as a function of condensing temperature for an ejector using $\mathrm{R} 141 \mathrm{~b}$ at $T_{g}=90^{\circ} \mathrm{C}$ and

$$
T_{e}=12^{\circ} \mathrm{C}
$$

The influence of the generator temperature on the critical condensing temperature/pressure can be easily determined at any given area ratio. For example, considering an area ratio, $A_{r}=7.25$ (Ejector 1-A in Table 3) that gives a critical condensing temperature between $35^{\circ} \mathrm{C}$ and $40^{\circ} \mathrm{C}$ at a generator temperature of $90^{\circ} \mathrm{C}$. Fig. 10 shows the $\mathrm{COP}$ at different generator temperatures as the condensing temperature changes. It is shown in Fig. 10 that the higher critical condensing temperatures obtained as the generator temperatures rise provide a larger window of operation in the critical mode without ejector breakdown. However, the entrainment ratio and subsequently the COP drop with soaring generator temperatures. The critical values of the COP are 0.594, 0.409, 0.282, 0.1952 and 0.1367 at generator temperatures of $70,80,90,100$ and $110^{\circ} \mathrm{C}$, respectively. The corresponding values of the critical condensing temperatures are 26.42, 31.66, 37.30, 43.09 and $49.00^{\circ} \mathrm{C}$, respectively. The reduction in the entrainment ratio and COP at higher generator temperatures for an ejector with a fixed mixing chamber cross-section is due to the significant surge in the primary flow rate and the corresponding decline in the secondary flow rate. 


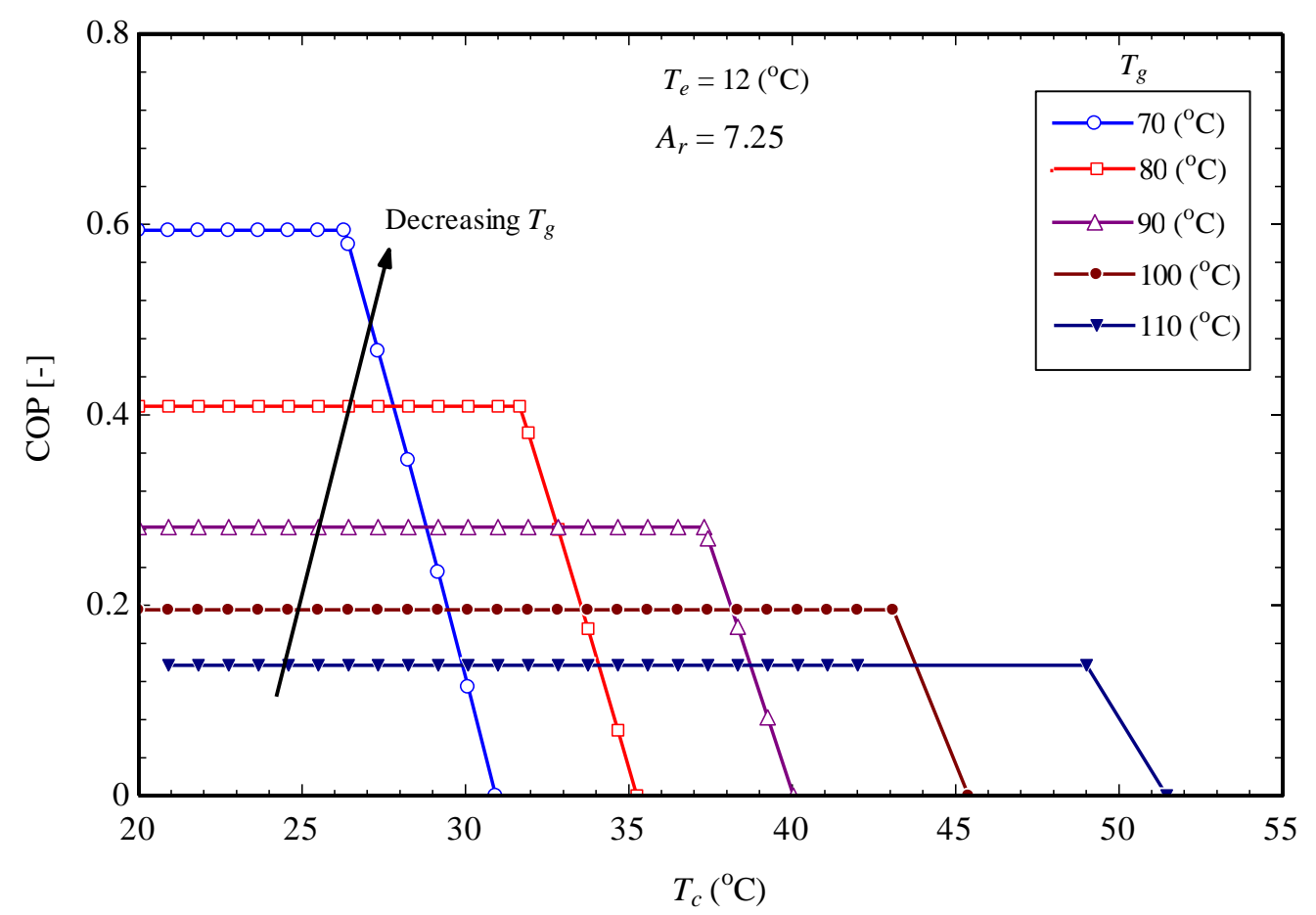

Fig.10. COP as a function of the condensing temperature at different values of the generator temperature using R141b as the working fluid

It is essential to determine the correct condensing temperature under which the ejector operates in the critical mode. This is made possible by plotting the ejector performance chart giving the entrainment ratio or COP at different condensing temperatures as the area ratio changes (Fig. 9) or as the generator temperature changes (Fig. 10). In these figures, the critical condensing temperature and the breakdown temperature are clearly indicated. Figure 11 is derived from Figs. (9) and (10) for different generator temperatures and area ratios with $T_{e}=8^{\circ} \mathrm{C}$. It depicts the variation of the critical condensing temperature as a function of the generator temperature at the considered area ratios. Using Figure 11, the required condensing temperature can be selected, and the generator temperature chosen under which the ejector operates in the critical mode. For example, with a condensing temperature of $35^{\circ} \mathrm{C}$ and an evaporator temperature of $8^{\circ} \mathrm{C}$, the ejector should operate at generator temperatures lower than $75^{\circ} \mathrm{C}, 83^{\circ} \mathrm{C}, 88^{\circ} \mathrm{C}, 97^{\circ} \mathrm{C}, 104^{\circ} \mathrm{C}$ and $110^{\circ} \mathrm{C}$ for the area ratios of $4.45,6.44,7.25,9.54,10.98$ and 12.89 , respectively when using R141b as the refrigerant. The critical condensing temperature goes up as the generator temperature rises and as the area ratio lessens. However, much smaller area ratios give lower COPs even though they give a wide range of condensing temperatures under which the ejector works in the critical mode. 


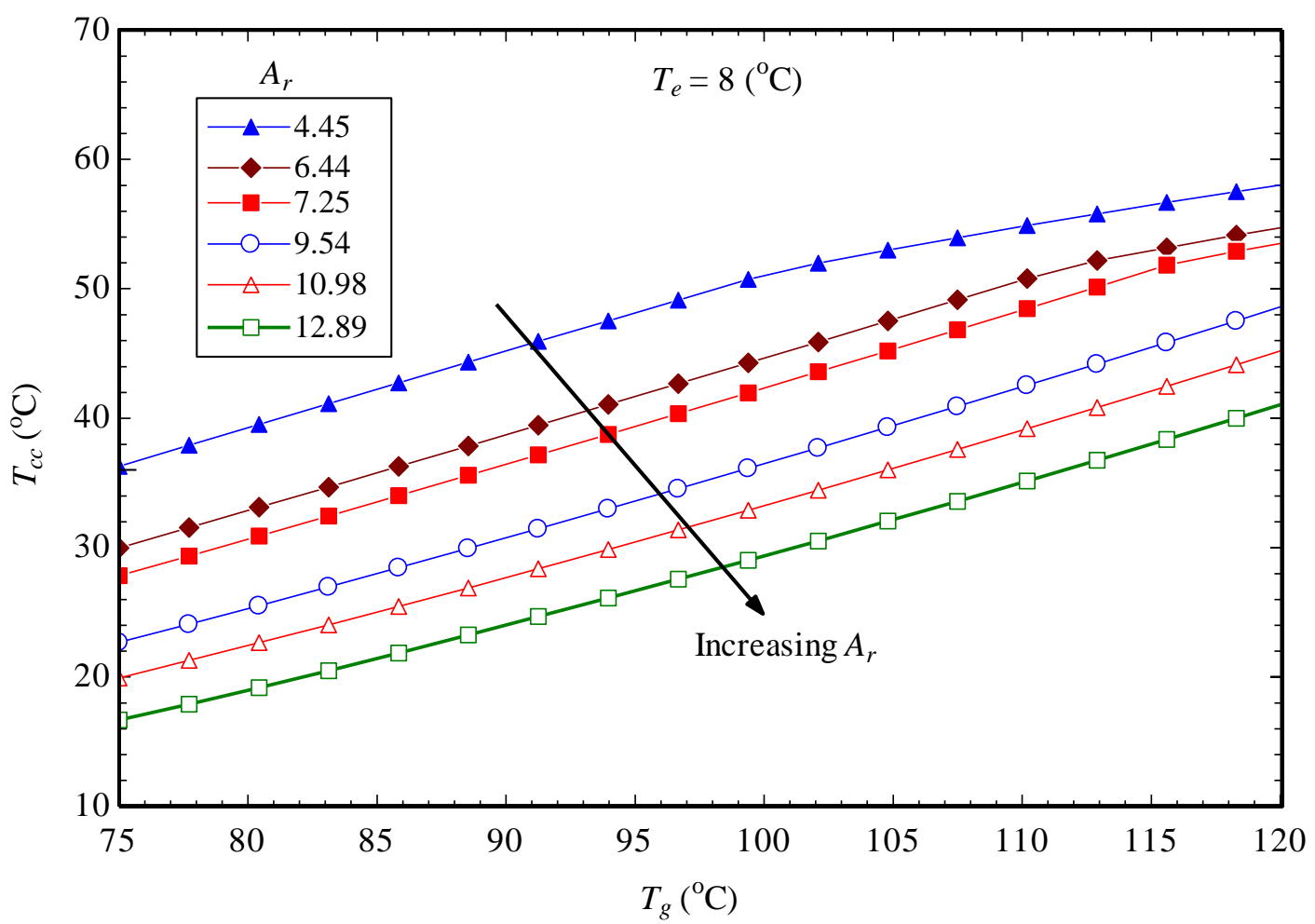

Fig. 11. Critical condensing temperature as a function of generator temperature at different area ratios for an ejector using $\mathrm{R} 141 \mathrm{~b}$ for $T_{e}=8^{\circ} \mathrm{C}$

The variation of the $\mathrm{COP}$ with condensing temperature at a generator temperature of $90^{\circ} \mathrm{C}$ and different evaporator temperatures is portrayed in Fig. 12. As depicted, increasing the evaporator temperatures gives higher COPs at a given condensing temperature. This is due to the lower pressure ratio and the ease with which the secondary flow can be entrained by the primary flow at higher evaporator pressures. It is also shown in Fig. 12 that as the evaporator temperature rises, the critical condensing temperature slightly increases. A higher evaporator pressure makes it possible for the secondary flow to remain chocked at slightly higher condensing temperatures. 


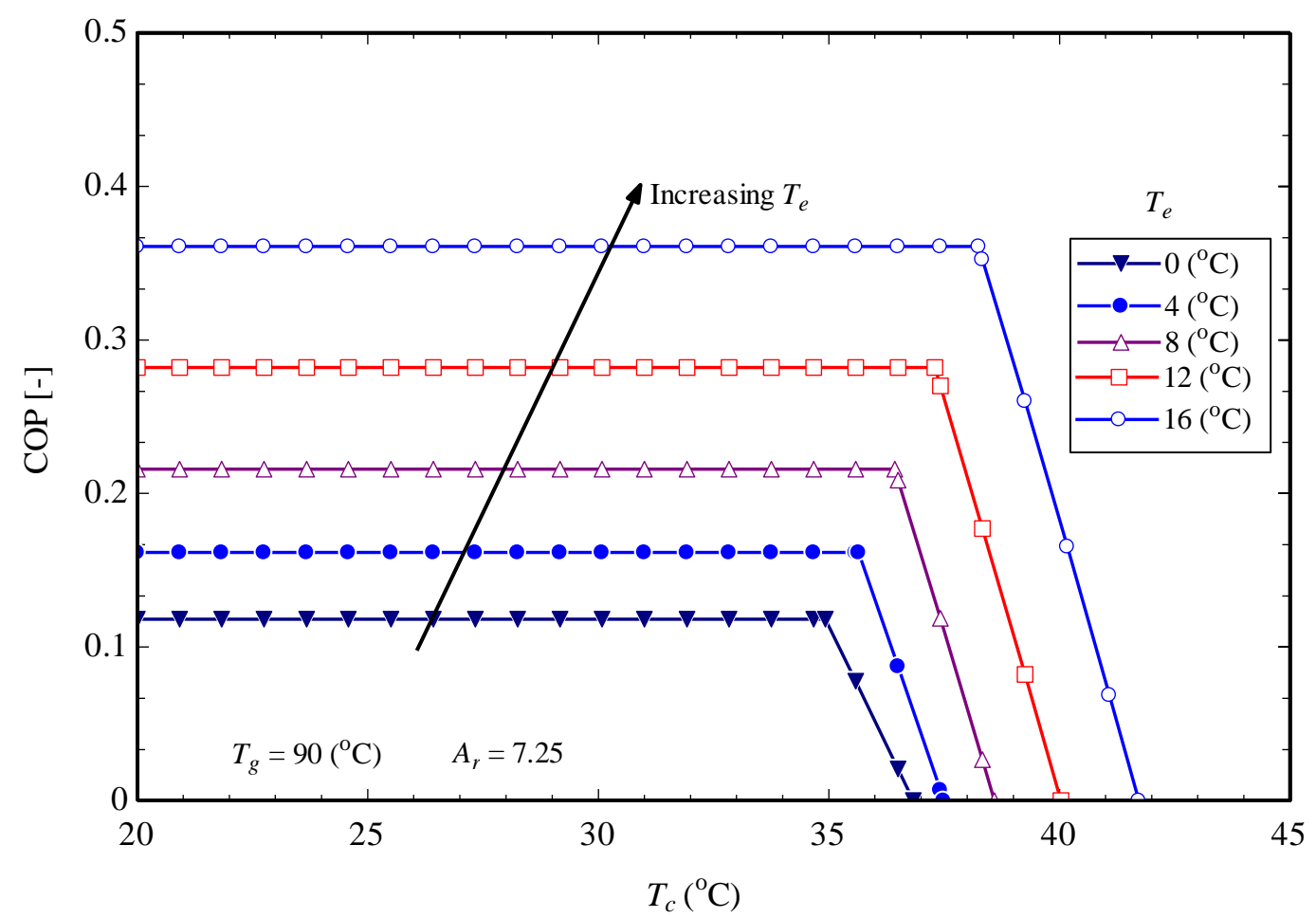

Fig. 12. COP as a function of condensing temperature at different evaporator temperatures for an ejector system using R141b with $T_{g}=90^{\circ} \mathrm{C}$ and $A_{r}=7.25$

As shown in this section, ejectors having the same area ratio give the same performance as shown in Figs. (7) and (8). Therefore, for the forthcoming analyses and discussions area ratios have been selected to cover the entire range considered in Figs. (7) and (8) in such a way that close or similar area ratios are not used. The area ratios selected for further analyses are: 4.45, 6.44, 7.25, 9.54, 10.98 and 12.76 with the corresponding geometries given in Table 3 (Ejectors 1_1, AA, 1-A, 2-B, 3_1 and 5_2, respectively). In the next section, the performance of an ejector refrigeration system working with the identified environmentally benign refrigerants is discussed.

\subsection{Performance comparison using environmentally benign refrigerants}

Using R141b, the different performance characteristics of the ejector refrigeration system have been discussed. However, as shown in Table 2, R141b is an ozone depleting substance and the other commonly used refrigerants R123 and R245fa are not environmentally benign. R123 is also ozone depleting while R245fa has a high GWP. Therefore, it becomes crucial to characterize performance of ejector refrigeration systems using environmentally benign working fluids. In this section, a comparative study on the performance of an ejector refrigeration system using different 
environmentally benign refrigerants is presented. For each refrigerant, the same trends as were obtained for R141b can be obtained as the area ratios, generator temperatures, condensing temperatures, and evaporator temperatures change.

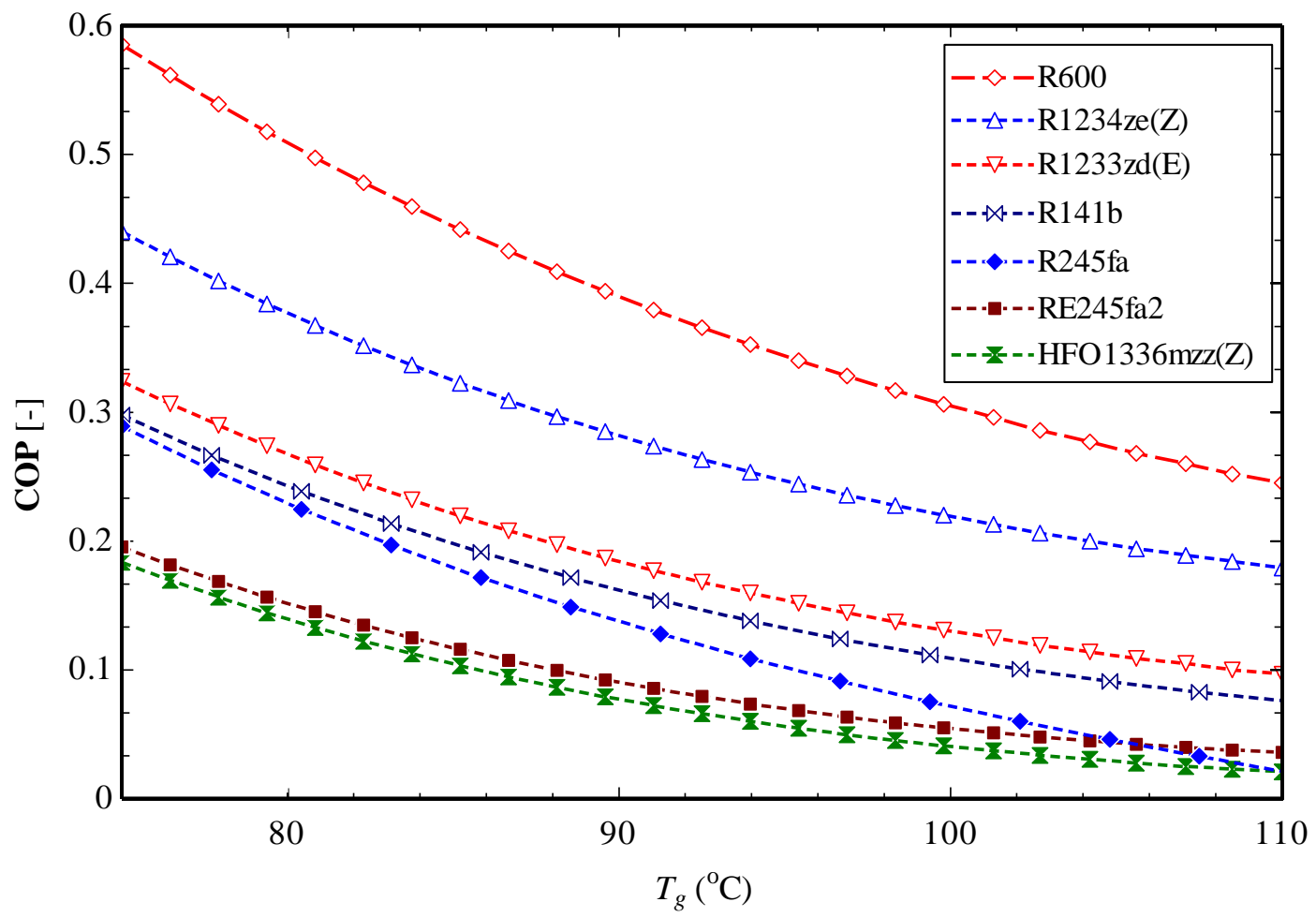

Fig.13. Critical COP as a function of generator temperature for the different refrigerants considered for $A_{r}=7.25$ and $T_{e}=4^{\circ} \mathrm{C}$.

Figure 13 shows the COP of different refrigerants as a function of the generator temperature for $A_{r}=7.25$ and $T_{e}=4^{\circ} \mathrm{C}$. As earlier shown and discussed for R141b, the COP diminishes with rising generator temperatures. In Fig. 13, R600 gives the highest COP of all the working fluids considered followed by R1234ze(Z), R1233zd(E) and R141b. The performance of R141b is also shown to be higher than that of R245fa, especially as the generator temperatures increase. As the generator temperatures rise, the performance of R245fa approaches that of RE245fa and HFO1336mzz(Z), the two refrigerants with the lowest performance. The high vapor pressures at the evaporator and generator inlets or the high latent heat of vaporization at the evaporator pressure or a combination of these, result in the improved performance of the system.

The higher the generator and evaporator vapor pressures, the more the flow rate of the primary flow, and the more the flow rate of the entrained secondary flow, respectively. As an example, for 
an ejector with $A_{r}=12.76$, operating with a generator temperature of $90^{\circ} \mathrm{C}$ and an evaporator temperature of $8^{\circ} \mathrm{C}$, the corresponding vapor pressures and mass flow rates for the ejector at the primary flow inlet and secondary flow inlet as well as the enthalpy change across the evaporator and the cooling capacity for each refrigerant can be obtained and compared. For R600, the vapor pressures are $1.25 \mathrm{MPa}$ and $0.14 \mathrm{MPa}$, the mass flow rates are $0.03377 \mathrm{~kg} / \mathrm{s}$ and $0.04248 \mathrm{~kg} / \mathrm{s}$, the enthalpy difference across the evaporator is $335.75 \mathrm{~kJ} / \mathrm{kg}$ giving a cooling capacity of $14 \mathrm{~kW}$. For $\mathrm{R} 1234 \mathrm{ze}(\mathrm{Z})$ the vapor pressures are $1.08 \mathrm{MPa}$ and $0.096 \mathrm{MPa}$, the mass flow rates are $0.4207 \mathrm{~kg} / \mathrm{s}$ and $0.03891 \mathrm{~kg} / \mathrm{s}$, the enthalpy change is $198.95 \mathrm{~kJ} / \mathrm{kg}$ giving a cooling capacity of $10 \mathrm{~kW}$. For $\mathrm{R} 1233 \mathrm{zd}(\mathrm{E})$ the vapor pressures are $0.833 \mathrm{MPa}$ and $0.0674 \mathrm{MPa}$, the mass flow rates are 0.0332 $\mathrm{kg} / \mathrm{s}$ and $0.0255 \mathrm{~kg} / \mathrm{s}$, the enthalpy variation is $181.87 \mathrm{~kJ} / \mathrm{kg}$ giving a cooling capacity of $4.64 \mathrm{~kW}$. For R245fa, the vapor pressures are 1.01 MPa and $0.075 \mathrm{MPa}$, the mass flow rates are $0.0412 \mathrm{~kg} / \mathrm{s}$, $0.02898 \mathrm{~kg} / \mathrm{s}$ with an enthalpy change across the evaporator of $178.43 \mathrm{~kJ} / \mathrm{kg}$ and a cooling capacity of $5.17 \mathrm{~kW}$.

Evidently, both the enthalpy changes across the evaporator and secondary flow vapor pressure, and subsequently the mass flow rate through the evaporator influence the ejector performance. The higher the vapor pressure of the secondary flow entering the evaporator and the higher enthalpy change (latent heat of vaporization), the better the performance. For the high performing R600 refrigerant, the vapor pressure at the evaporator inlet is $86.6 \%$ great than that of R245fa, its enthalpy change across the evaporator is $88.2 \%$ greater than that of R245fa. The same comparison is true at other area ratios.

Even though R600 gives the highest possible performance values of the considered refrigerants, its flammability rating makes its use risky and should be considered with care. As such, of the considered working fluids, $\mathrm{R} 1234 \mathrm{ze}(\mathrm{Z})$ and $\mathrm{R} 1233 \mathrm{zd}(\mathrm{E})$ appear to be the best suitable replacements for R141b and R245fa owing to their better performance, low GWP, no ODP, and non-toxicity. They are also not as flammable as R600.

Figure 14 represents the critical condensing temperature for the refrigerants considered as a function of the generator temperature. As portrayed, the critical condensing temperature becomes higher as the generator temperature rises as already demonstrated in Fig.11. At a given generator temperature, there is no significant difference in the critical condensing temperatures of the different refrigerants considered. This is likely because the considered refrigerants have nearly the 
same vapor pressures at the considered generator and evaporator temperatures. For the considered refrigerants, the difference between the minimum and the maximum critical condensing temperature at a certain generator temperature is about $3^{\circ} \mathrm{C}$. Using Fig. 14, the critical condensing temperature at any generator temperature for each refrigerant can be obtained. The range of the actual condensing temperatures to ensure optimal performance can then be determined for a specified application.

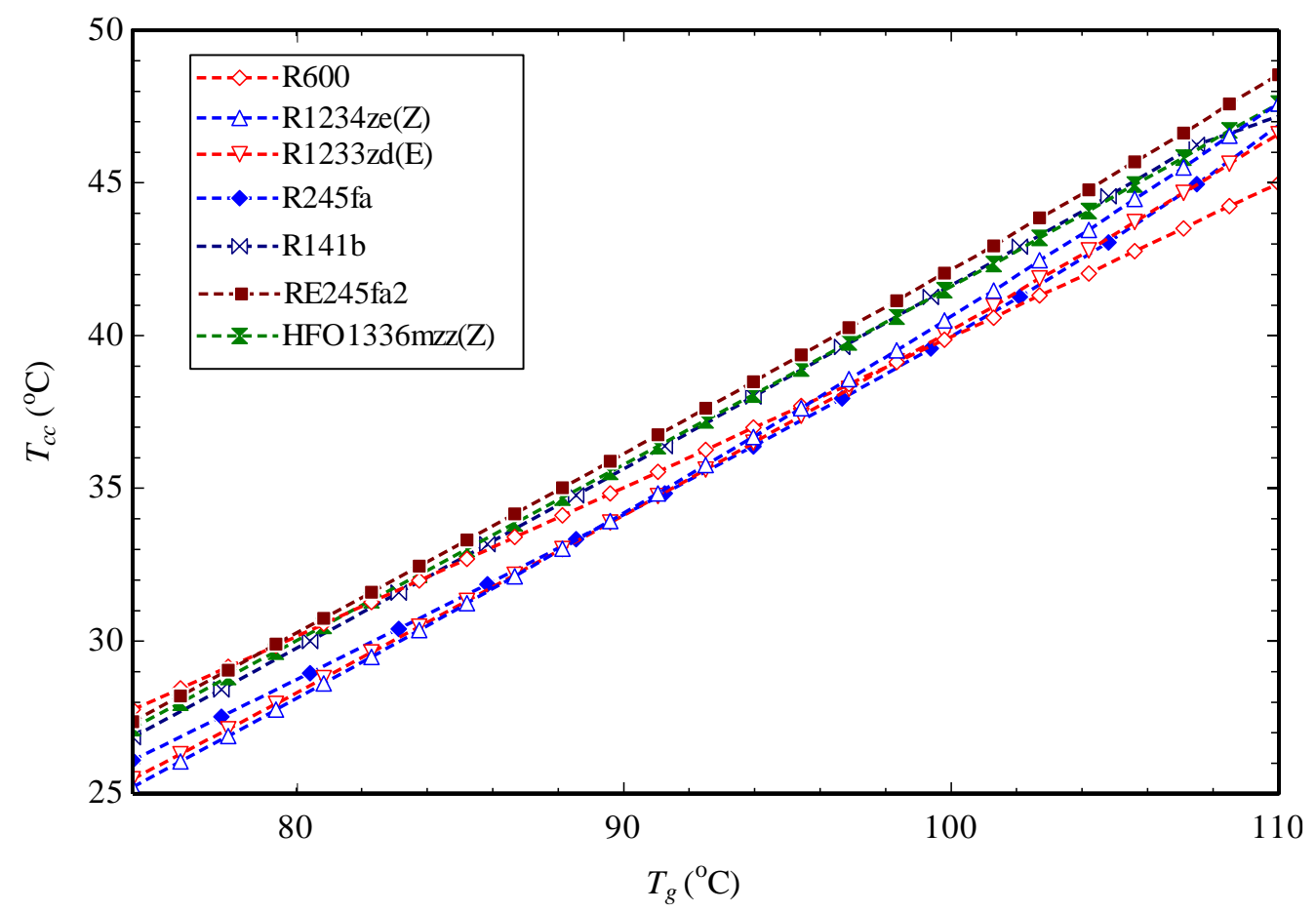

Fig. 14. Critical condensing temperature for the alternative refrigerants as a function of generator temperature.

Overall, RE245fa, HFO1336mzz(Z) and R141b show the highest critical condensing temperature in that order for the generator temperatures considered. However, the performance of RE245fa and $\mathrm{HFO} 1336 \mathrm{mzz}(\mathrm{Z})$ is the lowest of the refrigerants used as depicted in Fig. 13. R1234ze(Z) and $\mathrm{R} 1233 \mathrm{zd}(\mathrm{E})$ have the lowest values of the critical condensing temperatures for most of the range of generator temperatures considered. These two refrigerants also showed higher performance, respectively after R600. To achieve the same critical condensing temperature as R141b or R245fa, a slightly higher generator temperature can be used for the alternative environmentally benign working fluids that gave better performance. As an example, at $T_{c c}=35^{\circ} \mathrm{C}, T_{g}=88^{\circ} \mathrm{C}$ for $\mathrm{R} 141 \mathrm{~b}$, 
the same critical condensing temperature is obtained with $T_{g}=92^{\circ} \mathrm{C}$ for R600, R1234ze(Z) and $\mathrm{R} 1233 \mathrm{zd}(\mathrm{E})$.

For $\mathrm{R} 1234 \mathrm{ze}(\mathrm{Z})$ and $1233 \mathrm{zd}(\mathrm{E})$, the refrigerants that were shown to be good replacements for $\mathrm{R} 141 \mathrm{~b}$ and R245fa; the effect of evaporator temperature on performance at different generator temperatures is shown in Fig. 15(a) and (b), respectively. As expected, better performance is obtained at higher evaporator temperatures owing to the reduced pressure lift and higher mass flow rate entrainment of the secondary flow. The performance is shown to wane as the generator temperature increases owing to the higher primary flow mass flow rate and thus reduced entrainment of the secondary flow for a fixed ejector geometry. It can also be seen that R1234ze(Z) shows better performance compared to R1233zd(E) as already shown in the Figs. 13. Figure 15(c) shows the COP as a function of evaporator temperature for R1234ze(Z), R1233zd(E), R245fa and R141b. As depicted, R1234ze(Z) and R1233zd(E) show better performance than R245fa and $\mathrm{R} 141 \mathrm{~b}$ at all the considered evaporator temperatures as discussed earlier.

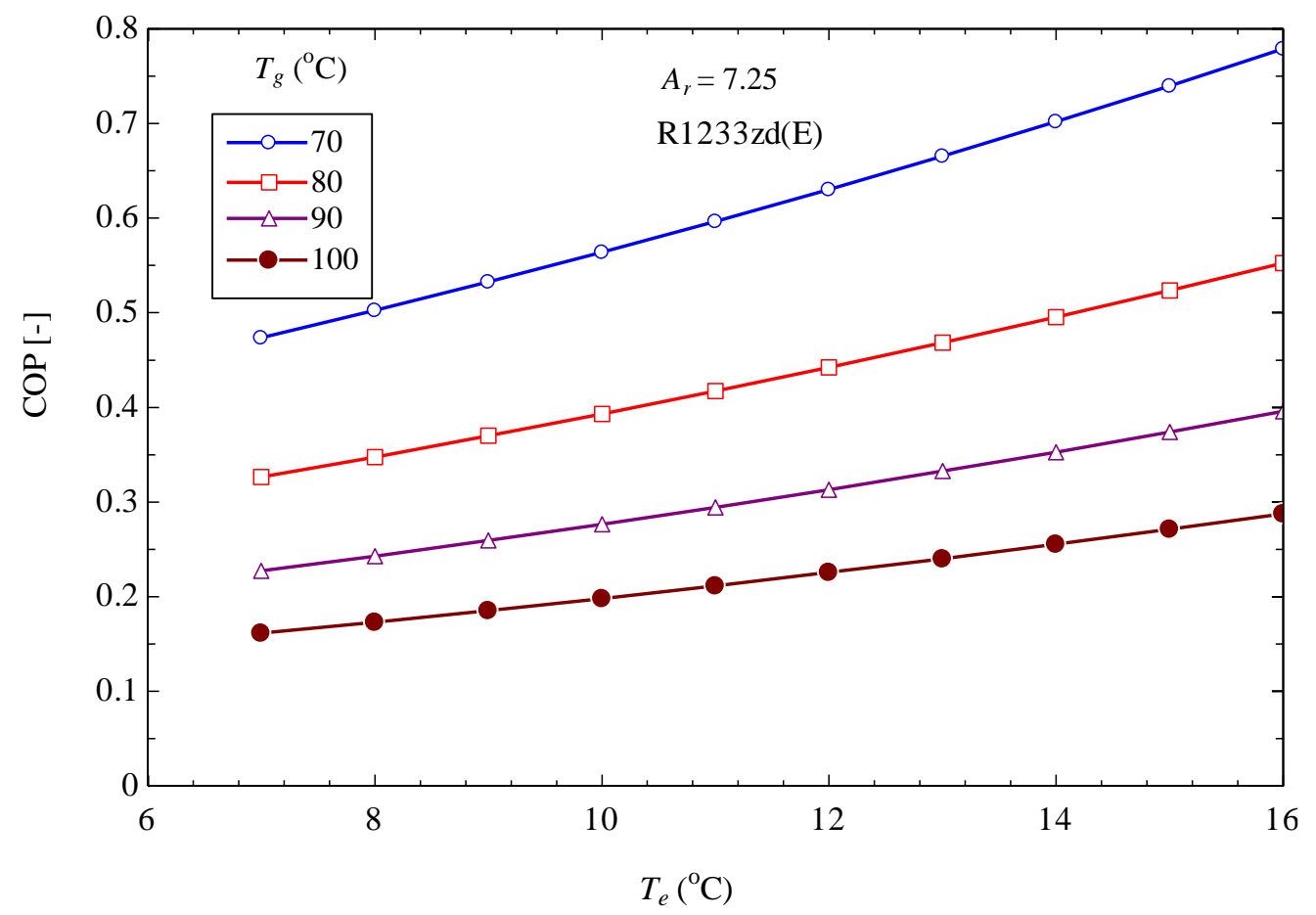

(a) 


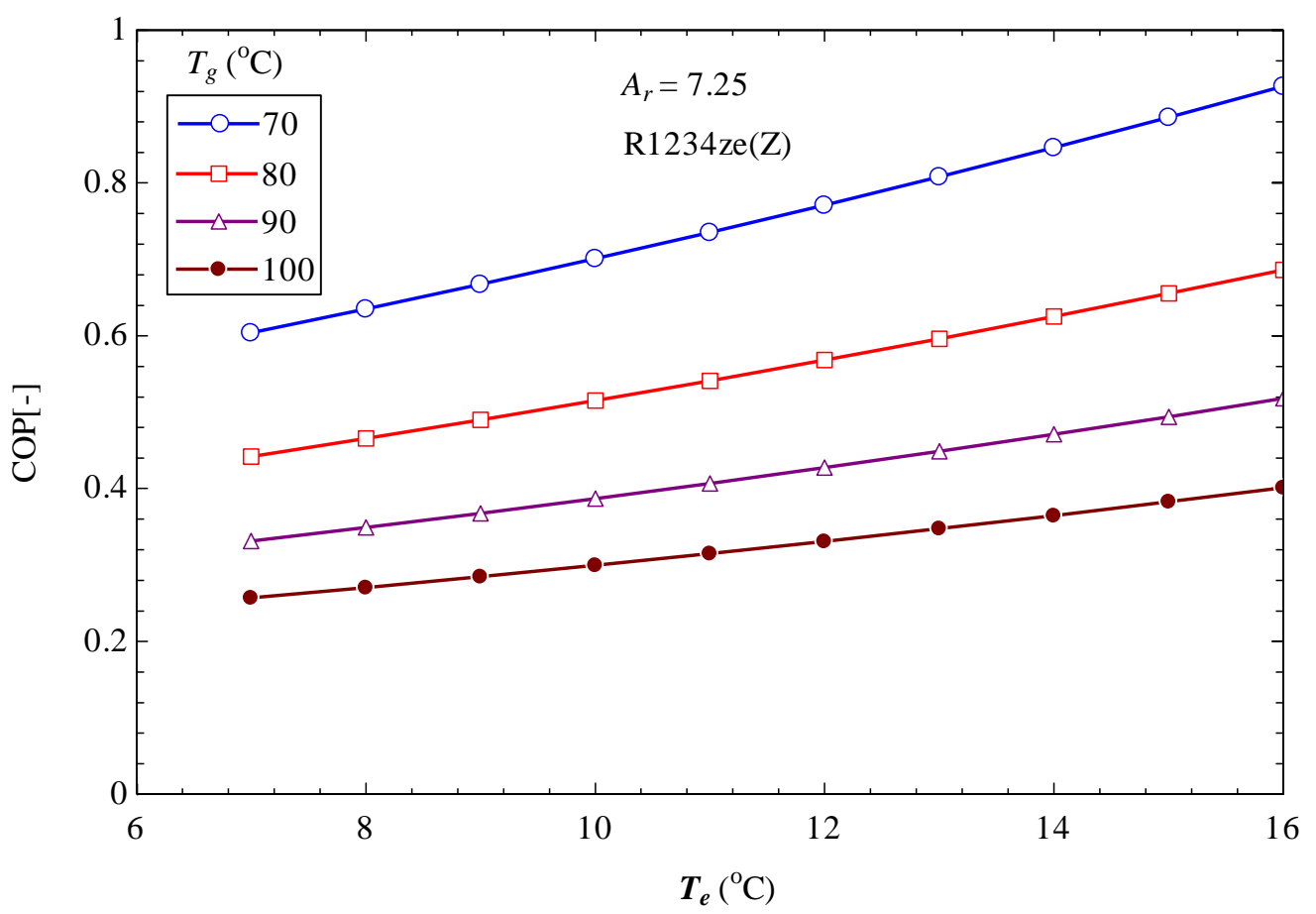

(b)

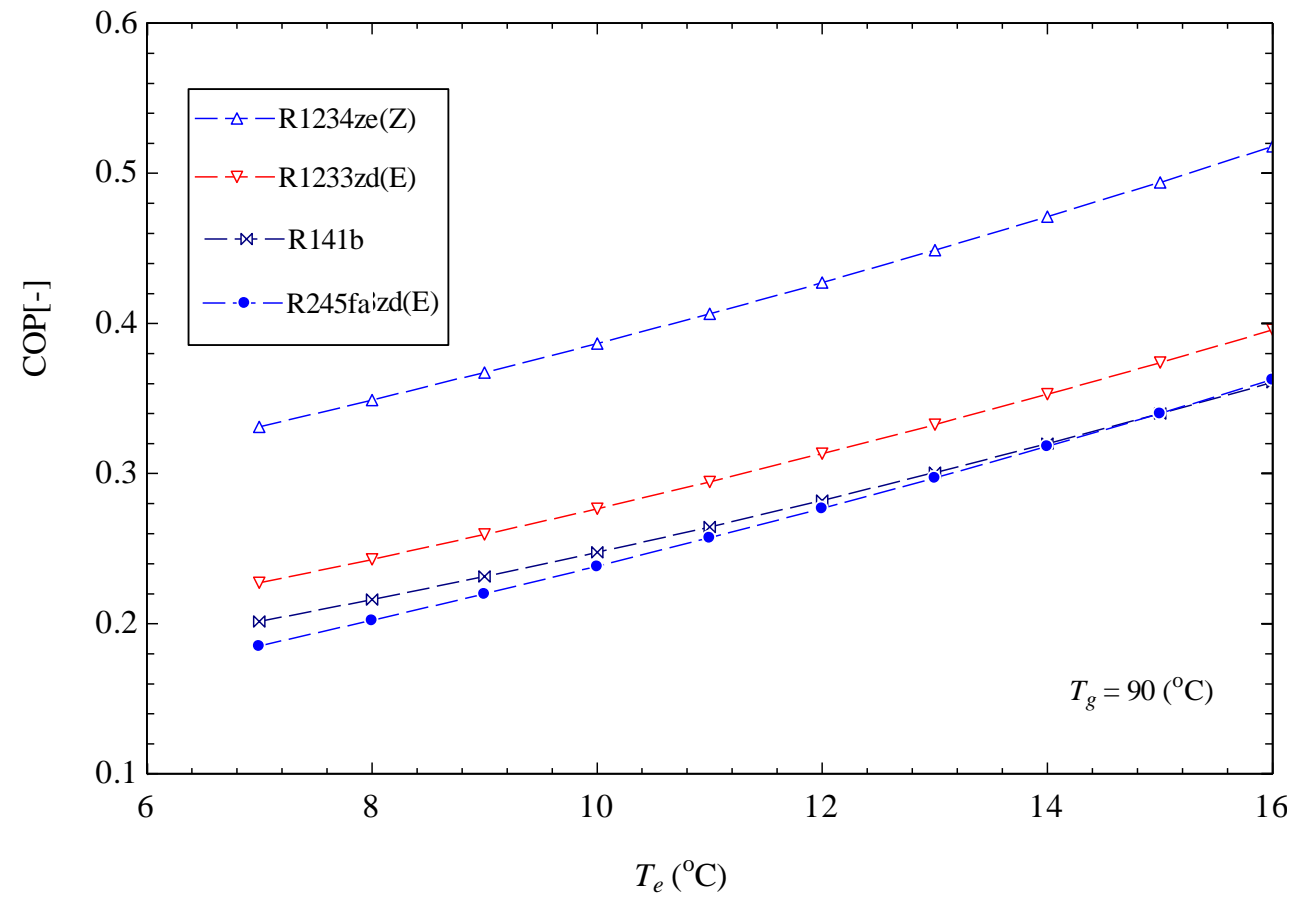

(c)

Fig. 15. Coefficient of performance as a function of evaporator temperature at different generator temperatures for an ejector area ratio, $A_{r}=7.25$ under the critical mode of operation for (a) $\mathrm{R} 1234 \mathrm{ze}(\mathrm{Z}),(\mathrm{b}) \mathrm{R} 1233 \mathrm{zd}(\mathrm{E})$, and (c) different refrigerants with $T_{g}=90^{\circ} \mathrm{C}$ 
From the foregoing discussion, R1233zd(E) and R1234ze(Z) are shown to be potential replacements for R141b and R245fa owing to their better performance, good environmental properties and desirable safety and toxicity ratings. In the succeeding section, an optimization study of an ejector system using these working fluids is undertaken.

\subsection{Ejector performance optimization}

At each area ratio and a given combination of condenser and evaporator temperature, there is a distinct generator temperature at which the performance of the ejector refrigeration system is optimal. Figure 16 (a) and (b) represent the distinct optimal performance for an ejector working with $\mathrm{R} 1234 \mathrm{ze}(\mathrm{Z})$ and $\mathrm{R} 1233 \mathrm{zd}(\mathrm{E})$, respectively at different area ratios for a condensing temperature of $35^{\circ} \mathrm{C}$ and an evaporator temperature of $8^{\circ} \mathrm{C}$.

At a given area ratio, with fixed evaporator and condenser temperatures, the COP and the entrainment ratio grow as the generator temperature rises, attain a maximum and then drop with further increase in the generator temperature. In the part of increasing COP/entrainment ratio, the condenser temperature is higher than the critical condensing temperature and the ejector performs in the subcritical mode. As the generator temperature rises, the critical condensing temperature increases and becomes equal to the condensing temperature. A further rise in the generator temperature makes the condensing temperature lower than the critical temperature of the higher generator temperatures. When the condensing temperature is within the range of the critical mode of operation $\left(T_{c c} \geq T_{c}\right)$, the ejector operates in the critical mode and the value of COP/entrainment ratio is equal to that at the critical point. Since it was shown that increasing the generator temperatures leads to a decline in the critical value of the COP or entrainment ratio, the COP and the entrainment ratio decline with rising generator temperatures after the optimal point of operation.

At a given area ratio, increasing the generator temperature increases the critical condensing temperature. Moreover, the $\mathrm{COP}$ at the optimal point of operation is higher for large area ratios than smaller ones. When extrapolated, the minimum generator temperatures to activate the ejector system can be obtained from Fig. 16 (a) and (b). Smaller area ratios require lower generator temperatures, whereas larger area ratios require higher pressures to entrain the right amount of the secondary flow and thus much higher generator temperatures. Therefore, the minimum generator temperature required for an ejector refrigeration system at given condenser and evaporator 
temperatures increases as the area ratio increases. Fig. 16 (b) obtained for an ejector working with R1233zd(E) shows the same trend as R1234ze(Z) in Fig. 16 (a). However, the optimal COP values at a given area ratio are lower than those of $\mathrm{R} 1234 \mathrm{ze}(\mathrm{Z})$, since this refrigerant was shown to perform better than all the considered refrigerants except R600. The same trends can be obtained for other working fluids and combinations of the evaporator and condenser temperatures.

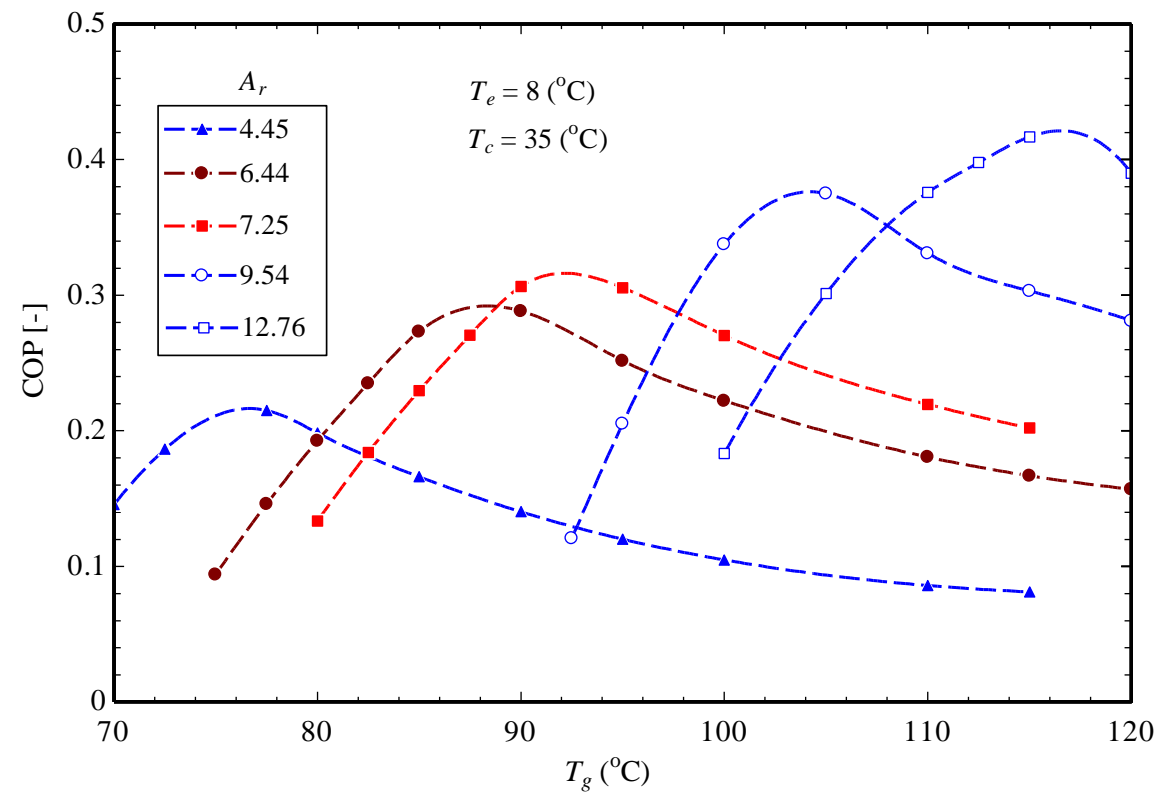

(a)

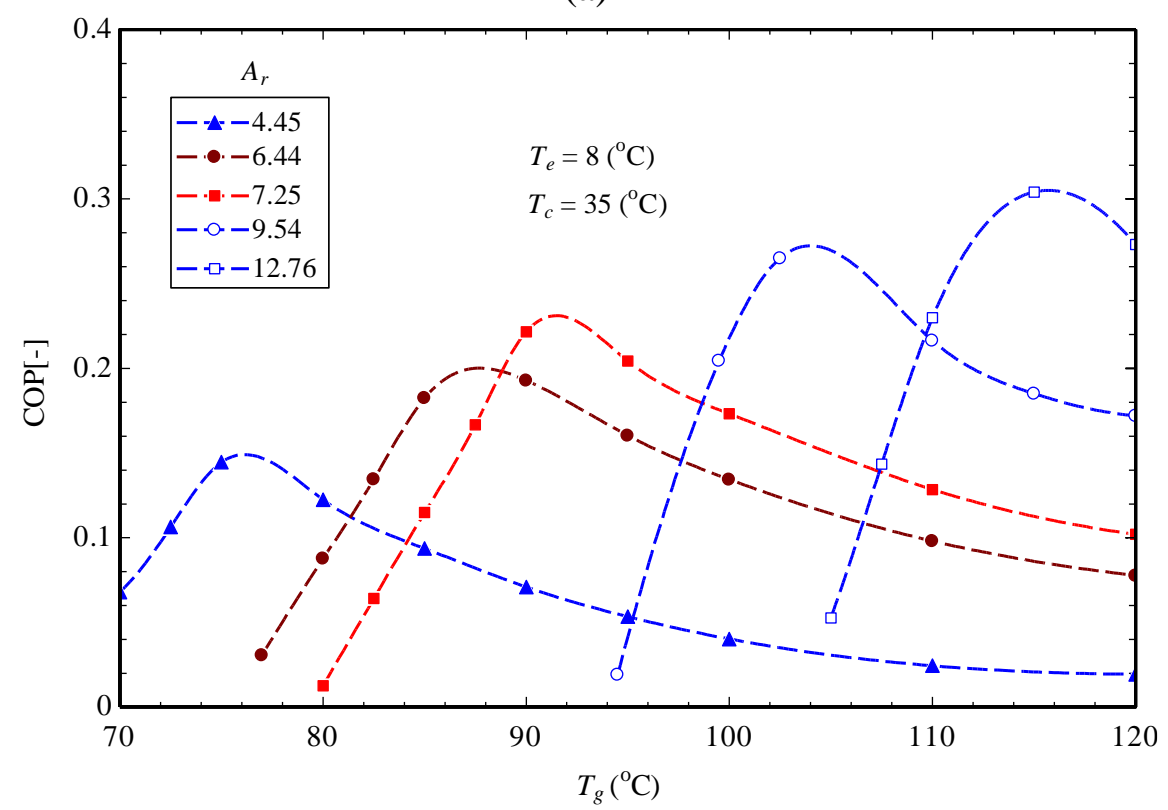

(b)

Fig. 16. $\mathrm{COP}$ as a function of generator temperature at different area ratios for $T_{e}=8^{\circ} \mathrm{C}$ and $T_{c}=$ $35^{\circ} \mathrm{C}$ with (a) R1234ze(Z), and (b) with R1233zd(E) 
At a given area ratio, different condensing temperatures can be considered, and optimum values of the generator temperature determined at which the ejector gives the highest COP. This alternative and more convenient way of determining the ejector optimal performance has been suggested in the present study. With this method, performance graphs can be plotted for known ejector geometries and evaporator temperatures and used to determine performance at each possible condensing temperature. Figure 17 demonstrates the variation of the COP with the generator temperature at $A_{r}=7.25$ and an evaporator temperature of $8^{\circ} \mathrm{C}$ for different condensing temperature with R1234ze(Z). As shown, for condensing temperatures greater or equal to $25^{\circ} \mathrm{C}$, there is an optimal generator temperature for each condensing temperature. Lower than this optimal value, the ejector is operating in the subcritical mode with only the primary flow chocked. At generator temperatures higher than the optimal value, the ejector operates in the critical mode with both the primary and secondary flows chocked as discussed in the preceding paragraphs.

Above the optimal generator temperature, the performance curve follows the critical curve for the previous condensing temperature. This indicates that at the current condensing temperature, the critical temperature is higher than the previous condensing temperature, thus the entrainment ratio or the COP stays constant. Figure 18 is a plot of the cooling capacity against generator temperature at different values of the condensing temperature for $A_{r}=7.25$ and $T_{e}=8^{\circ} \mathrm{C}$ with $\mathrm{R} 1233 \mathrm{zd}(\mathrm{E})$ as the working fluid. The same trend as was obtained in Fig.17 for the COP exists. It is also worth noting that the optimal generator temperature in Figs. 17 and 18 at $35^{\circ} \mathrm{C}$ should correspond to the values in Figs. 16 (a) and (b), respectively at the same area ratio $\left(A_{r}=7.25\right)$.

It can also be deduced from Figs. 17 and 18 that lower condenser temperatures give the best performance and require lower generator temperatures as expected. This is due to the lower pressure lift at low condensing temperatures compared to higher ones. However, depending on the climate or the function of the ejector system, the condensing temperature is always limited by the prevailing outdoor conditions. In the cooling mode when a temperature of $27^{\circ} \mathrm{C}$ is required, the ejector must reject heat to an outdoor environment with temperatures above $30^{\circ} \mathrm{C}$. Thus, condensing temperatures of $35^{\circ} \mathrm{C}$ and above will be common for efficient heat transfer performance of the condenser. For temperatures lower than $20^{\circ} \mathrm{C}$, the optimal generator temperature is lower than $70^{\circ} \mathrm{C}$ and out of the range of temperatures considered. Similar trends can be obtained for different working fluids. 


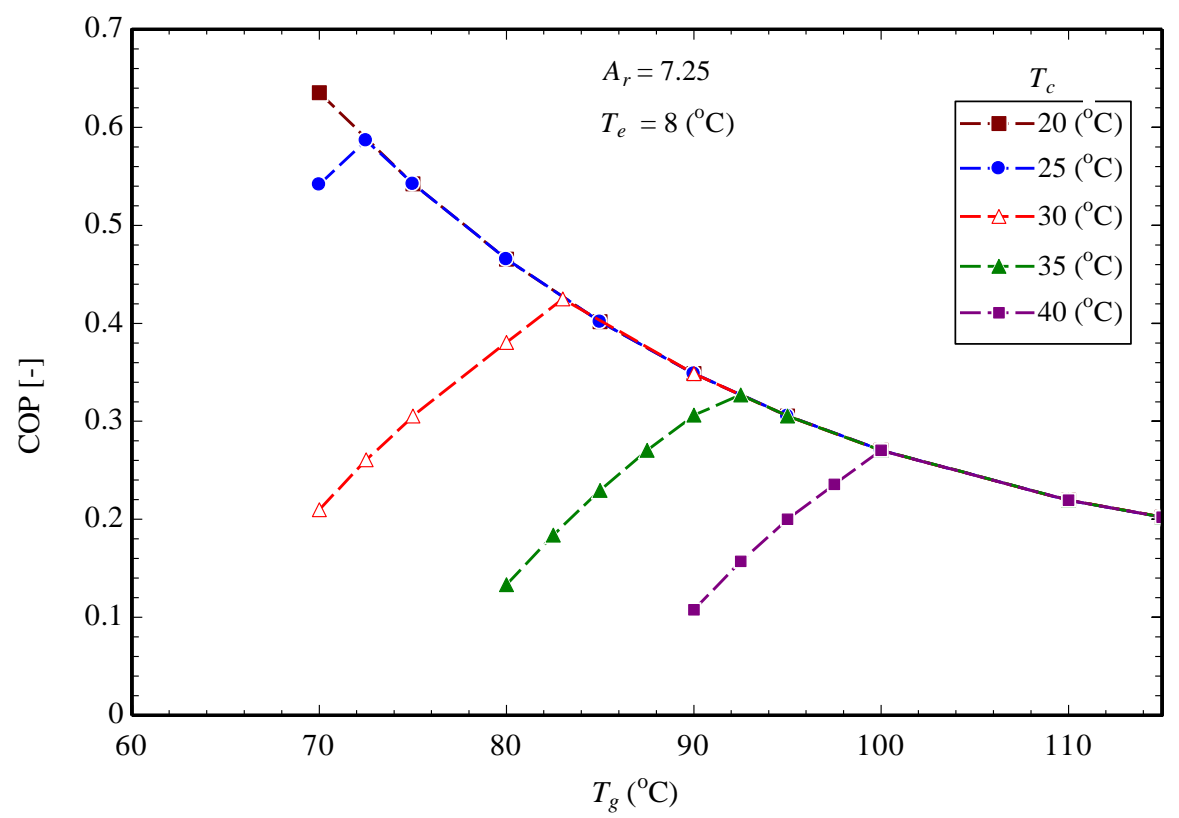

Fig. 17. COP as a function of generator temperature at $T_{e}=8^{\circ} \mathrm{C}$ and $A_{r}=7.25$ for different condensing temperatures with R1234ze(Z) as the working fluid.

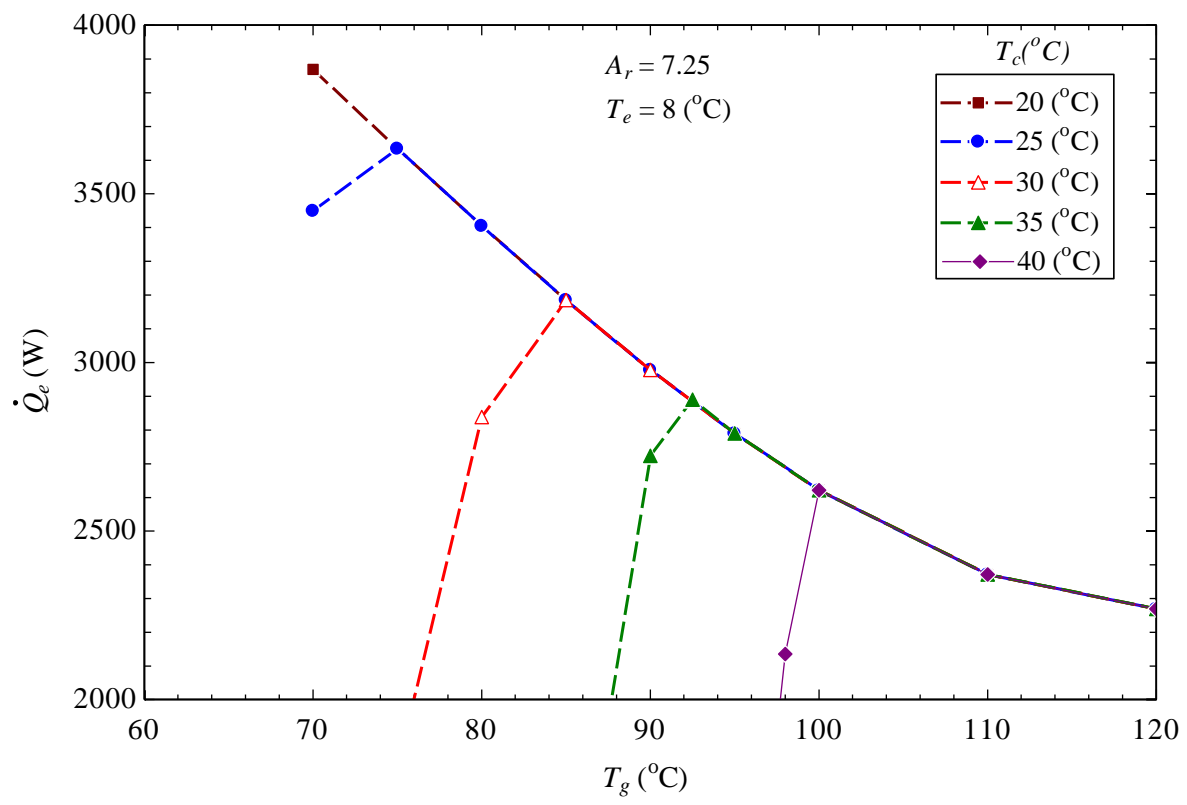

Fig. 18. Cooling capacity as a function of generator temperature at $T_{e}=8^{\circ} \mathrm{C}$ and $A_{r}=7.25$ for different condensing temperatures with $\mathrm{R} 1233 \mathrm{zd}(\mathrm{E})$ as the working fluid.

For different area ratios, Tables 6 to 9 shows a summary of the optimal performance parameters for the refrigerants with low GWP and ODP values, which have been shown to be promising replacements for R141b and R245fa. A table for R141b is included for comparison purposes. As the tables show, the optimal entrainment ratio and the optimal COP increase as the area ratio 
increases. With higher area ratios, the entrained secondary flow rate rises, increasing the entrainment ratio, the COP, and the cooling capacity. But, this increase is possible with an increase in the generator temperature. The optimal cooling capacity increases as the area ratio increases except for the case of $A_{r}=10.89$, where the cooling capacity is much smaller. This is attributed to the smaller nozzle throat area for this ejector compared to the other ejector geometries, implying less primary flow rate, and therefore the less entrained secondary flow rate. It is also shown that the critical condensing temperatures at the optimal generator temperatures are above the condensing temperature for each ejector geometry. This is expected since the ejector is expected to give better performance when operating in the critical mode $\left(P_{c c} \geq P_{c}\right)$. The optimum performance values are higher for R600, R1234ze(Z), R1233zd(E) in that order than for R141b as already discussed.

Table 6: Optimal performance parameters for an ejector working with $\mathrm{R} 600$ at $T_{e}=8^{\circ} \mathrm{C}$ and $T_{c}=35^{\circ} \mathrm{C}$

\begin{tabular}{ccccccc}
\hline \multicolumn{7}{c}{ Optimal values } \\
\hline & $T_{g}\left({ }^{\circ} \mathrm{C}\right)$ & $\mu$ & $\mathrm{COP}$ & $\dot{Q}_{e}(\mathrm{~kW})$ & $T_{c c}\left({ }^{\circ} \mathrm{C}\right)$ \\
\hline \multirow{4}{*}{$A_{r}$} & 4.45 & 75.2 & 0.4679 & 0.3597 & 2.207 & 36.11 \\
& 6.44 & 84.6 & 0.6102 & 0.4549 & 3.277 & 35.75 \\
& 7.25 & 89.5 & 0.6362 & 0.4667 & 11.002 & 36.43 \\
& 9.54 & 97.5 & 0.7673 & 0.5526 & 13.365 & 35.81 \\
& 10.98 & 106.5 & 0.7876 & 0.5560 & 2.761 & 37.25 \\
& 12.76 & 112.5 & 0.8586 & 0.6012 & 13.409 & 36.49 \\
\hline
\end{tabular}

Table 7: Optimal performance parameters for an ejector working with $\mathrm{R} 1234 \mathrm{ze}(\mathrm{Z})$ at $T_{e}=8^{\circ} \mathrm{C}$ and $T_{c}=35^{\circ} \mathrm{C}$

\begin{tabular}{ccccccc}
\hline \multicolumn{7}{c}{ Optimal values } \\
\hline & $T_{g}\left({ }^{\circ} \mathrm{C}\right)$ & $\mu$ & COP & $\dot{Q}_{e}(\mathrm{~kW})$ & $T_{c c}\left({ }^{\circ} \mathrm{C}\right)$ \\
\hline \multirow{4}{*}{$A_{r}$} & & 80.1 & 0.2398 & 0.1984 & 0.888 & 38.32 \\
& 4.45 & 90.3 & 0.3154 & 0.2883 & 1.534 & 37.64 \\
& 7.25 & 92.5 & 0.3775 & 0.3062 & 5.098 & 36.42 \\
& 9.54 & 104.3 & 0.4575 & 0.3310 & 7.055 & 37.21 \\
& 10.98 & 110.0 & 0.5044 & 0.4251 & 1.507 & 36.95 \\
& 12.76 & 116.2 & 0.5556 & 0.4468 & 7.563 & 37.26 \\
\hline
\end{tabular}


Table 8: Optimal performance parameters for an ejector working with $\mathrm{R} 1233 \mathrm{zd}(\mathrm{E})$ at $T_{e}=8^{\circ} \mathrm{C}$ and $T_{c}=35^{\circ} \mathrm{C}$

\begin{tabular}{ccccccc}
\hline \multicolumn{7}{c}{ Optimal values } \\
\hline & & $T_{g}\left({ }^{\circ} \mathrm{C}\right)$ & $\mu$ & $\mathrm{COP}$ & $\dot{Q}_{e}(\mathrm{~kW})$ & $T_{c c}\left({ }^{\circ} \mathrm{C}\right)$ \\
\hline \multirow{4}{*}{$A_{r}$} & 4.45 & 75.4 & 0.1842 & 0.1445 & 0.446 & 36.20 \\
& 6.44 & 89.5 & 0.2568 & 0.1928 & 0.798 & 38.23 \\
& 7.25 & 93.2 & 0.2844 & 0.2215 & 2.789 & 38.62 \\
& 9.54 & 102.5 & 0.3633 & 0.2163 & 3.600 & 38.50 \\
& 10.98 & 108.0 & 0.3808 & 0.2725 & 0.798 & 38.20 \\
& 12.76 & 114.8 & 0.4284 & 0.3041 & 3.958 & 37.40 \\
\hline
\end{tabular}

Table 9: Optimal performance parameters for an ejector working with $\mathrm{R} 141 \mathrm{~b}$ at $T_{e}=8^{\circ} \mathrm{C}$ and $T_{c}=35^{\circ} \mathrm{C}$

\begin{tabular}{ccccccc}
\hline \multicolumn{7}{c}{ Optimal values } \\
\hline & $T_{g}\left({ }^{\circ} \mathrm{C}\right)$ & $\mu$ & $\mathrm{COP}$ & $\dot{Q}_{e}(\mathrm{~kW})$ & $T_{c c}\left({ }^{\circ} \mathrm{C}\right)$ \\
\hline \multirow{4}{*}{$A_{r}$} & 4.45 & 74.8 & 0.1819 & 0.1484 & 0.319 & 36.27 \\
& 6.44 & 84.5 & 0.2183 & 0.1709 & 0.495 & 35.46 \\
& 7.25 & 90.1 & 0.2751 & 0.2159 & 2.007 & 36.51 \\
& 9.54 & 100.0 & 0.3207 & 0.2454 & 2.331 & 37.80 \\
& 10.98 & 103.5 & 0.3628 & 0.2763 & 0.485 & 35.22 \\
& 12.76 & 107.4 & 0.3919 & 0.2947 & 3.009 & 35.11 \\
\hline
\end{tabular}

\subsection{Conclusion}

In this paper, an improved 1-D numerical model for the analysis of the performance of an ejector refrigeration system has been developed and validated. Further, the model has been extended to the analysis of an ejector working with different dry and isentropic working fluids with compressibility factor comparable to those of R141b and R245fa. Correlations of ejector coefficients that give better agreement with experimental data were derived using regression analysis and were presented for R141b, R245fa and a combination of the two refrigerants. The developed model predicted performance within $\pm 5.5 \%$ when compared with experimental data for $\mathrm{R} 141 \mathrm{~b}$ and R245fa available in the literature. The model that combines the two refrigerants predicts the entrainment ratio within $\pm 7 \%$ for the R141b and within $\pm 6.5 \%$ for the R245fa ejector. The combined model predicts the cooling capacity of an ejector working with R365mfc within $\pm 9 \%$ and the coefficient of performance within $\pm 11 \%$. Overall, the developed model showed better agreement with experimental results compared to other studies available in the literature that use the same modeling approach. 
Using the developed model, ejector performance was characterized using R141b as the working fluid. Ejector performance under the critical mode of operation improves as the generator temperatures at a given area ratio and the area ratio at a given generator temperature increase. The decline in performance at higher generator temperatures is attributed to the much higher mass flow rates of the primary flow and the reduced mass flow rates of the entrained secondary flow as generator temperatures increase. At a given generator temperature, increasing the area ratio increases the amount of the entrained secondary flow thus improving performance. The critical condensing temperature drops as the generator temperature reduces and as the area ratio rises. The critical COPs at generator temperatures of $70,80,90,100$ and $110^{\circ} \mathrm{C}$ were obtained as 0.594 , $0.409,0.282,0.195$ and 0.137 , respectively with corresponding critical condensing temperatures of $26.42,31.66,37.30,43.09$ and $49.00^{\circ} \mathrm{C}$, respectively for an ejector with an area ratio of 7.25.

Moreover, in the study of ejector system performance with alternative environmentally benign refrigerants, R600, R1234ze(Z), R1233zd(E), RE245fa2, and HFO1336mzz(Z) were specifically considered as replacements for the commonly used R141b and R245fa refrigerants. For the range of generator temperatures considered, R600, R1234ze(Z) and R1233zd(E) in that order, showed the best performance. Each of the entrainment ratio, the COP, and the cooling capacity at any given area ratio for $\mathrm{R} 600, \mathrm{R} 1234 \mathrm{ze}(\mathrm{Z})$ and $\mathrm{R} 1233 \mathrm{zd}(\mathrm{E})$ were comparably higher than those of the other refrigerants. Of all the refrigerants, $\mathrm{HFO} 1336 \mathrm{mzz}(\mathrm{Z})$ gave the lowest values of the entrainment ratio, COP and cooling capacity. Since R600 is flammable, the two HFO refrigerants, R1234ze(Z) and $\mathrm{R} 1233 \mathrm{zd}(\mathrm{E})$ are potential working fluids for an ejector refrigeration system to replace $\mathrm{R} 141 \mathrm{~b}$ and R245fa.

Furthermore, it has been shown that there is an optimal generator temperature at a given area ratio and a combination of evaporator and condensing temperatures that gives maximum performance for each refrigerant. The optimum COP was in the range 0.35 to 0.60 for R600, 0.20 to 0.45 for R1234ze(Z), 0.14 to 0.30 for R1233zd(E) compared to 0.15 to 0.29 for R141b for the range of parameters considered.

\subsection{Acknowledgements}

The authors acknowledge funding from the Canadian Research Chairs Program and the Natural Sciences and Engineering Research Council (NSERC). 


\subsection{References}

[1] Edberg O, Waddelove A, Gibson G. Space heating and cooling. IEA ETSAP Technology Brief. IEA ETSAP 2012; R02:1-10.

[2] Ullah KR, Saidur R, Ping HW, Akikur RK, Shuvo NH. A review of solar thermal refrigeration and cooling methods. Renewable and Sustainable Energy Reviews 2013;24:499-513.

[3] CanmetENERGY. Capturing the Value of Thermal Energy-Innovations in Ejector Technology from CanmetENERGY. Natural Resources Canada 2015; M154-82/2015E-PDF:1-2.

[4] Keenan J, Henry, Neumann EP, Lustwerk F. An investigation of ejector design by analysis and experiment. Journal of Applied Mechanics Trans ASME 1950;17:299-309.

[5] Huang BJ, Chang JM, Wang CP, Petrenko VA. A 1-D analysis of ejector performance. International Journal of Refrigeration 1999;22:354-64.

[6] Chen W, Shi C, Zhang S, Chen H, Chong D, Yan J. Theoretical analysis of ejector refrigeration system performance under overall modes. Applied Energy 2017;185:2074-84.

[7] Aphornratana S., Chungpaibulpatana S., Srikhirin P. Experimental investigation of an ejector refrigerator: Effect of mixing chamber geometry on system performance. International Journal of Energy Research 2001;25:397-411.

[8] Yapıcı R, Ersoy HK, Aktoprakoğlu A, Halkacı HS, Yiğit O. Experimental determination of the optimum performance of ejector refrigeration system depending on ejector area ratio. International Journal of Refrigeration 2008;31:1183-9.

[9] Yapıc1 R. Experimental investigation of performance of vapor ejector refrigeration system using refrigerant R123. Energy Conversion and Management 2008;49:953-61.

[10] Thongtip T, Aphornratana S. An experimental analysis of the impact of primary nozzle geometries on the ejector performance used in R141b ejector refrigerator. Applied Thermal Engineering 2017;110:89-101.

[11] García del Valle J, Saíz Jabardo JM, Castro Ruiz F, San José Alonso JF. An experimental investigation of a R-134a ejector refrigeration system. International Journal of Refrigeration 2014;46:105-13.

[12] Selvaraju A, Mani A. Experimental investigation on R134a vapour ejector refrigeration system. International Journal of Refrigeration 2006;29:1160-6.

[13] Yan J, Chen G, Liu C, Tang L, Chen Q. Experimental investigations on a R134a ejector applied in a refrigeration system. Applied Thermal Engineering 2017;110:1061-5.

[14] Śmierciew K, Gagan J, Butrymowicz D, Łukaszuk M, Kubiczek H. Experimental investigation of the first prototype ejector refrigeration system with HFO-1234ze(E). Applied Thermal Engineering 2017;110:115-25.

[15] Li F, Li R, Li X, Tian Q. Experimental investigation on a R134a ejector refrigeration system under overall modes. Applied Thermal Engineering 2018;137:784-91.

[16] Shestopalov KO, Huang BJ, Petrenko VO, Volovyk OS. Investigation of an experimental ejector refrigeration machine operating with refrigerant R245fa at design and off-design working 
conditions. Part 2. Theoretical and experimental results. International Journal of Refrigeration 2015;55:212-23.

[17] Shestopalov KO, Huang BJ, Petrenko VO, Volovyk OS. Investigation of an experimental ejector refrigeration machine operating with refrigerant R245fa at design and off-design working conditions. Part 1. Theoretical analysis. International Journal of Refrigeration 2015;55:201-11.

[18] Chen W, Liu M, Chong D, Yan J, Little AB, Bartosiewicz Y. A 1D model to predict ejector performance at critical and sub-critical operational regimes. International Journal of Refrigeration 2013;36:1750-61.

[19] Ouzzane M, Aidoun Z. Model development and numerical procedure for detailed ejector analysis and design. Applied Thermal Engineering 2003;23:2337-51.

[20] Hassanain M, Elgendy E, Fatouh M. Ejector expansion refrigeration system: Ejector design and performance evaluation. International Journal of Refrigeration 2015;58:1-13.

[21] Li F, Tian Q, Wu C, Wang X, Lee J. Ejector performance prediction at critical and subcritical operational modes. Applied Thermal Engineering 2017;115:444-54.

[22] Li F, Chang Z, Tian Q, Wu C, Wang X. Performance Predictions of Dry and Wet Vapors Ejectors Over Entire Operational Range. Energies 2017;10.

[23] Zegenhagen MT, Ziegler F. A one-dimensional model of a jet-ejector in critical double choking operation with R134a as a refrigerant including real gas effects. International Journal of Refrigeration 2015;55:72-84.

[24] The European Parliament and the Council of the European Union. Regulation (EU) No. $517 / 2014$ of the European Parliament and of the Council of 16 April 2014 on fluorinated greenhouse gases and repealing Regulation (EC) No. 842/2006. Official Journal of the European Union 2014; L150:195-230.

[25] Cizungu K, Mani A, Groll M. Performance comparison of vapour jet refrigeration system with environment friendly working fluids. Applied Thermal Engineering 2001;21:585-98.

[26] Ozone Secretariat. Handbook for the Montreal Protocol on Substances that Deplete the Ozone Layer. UNEP, Nairobi, Kenya 2006; 1-743.

[27] Dahmani A, Aidoun Z, Galanis N. Optimum design of ejector refrigeration systems with environmentally benign fluids. International Journal of Thermal Sciences 2011;50:1562-72.

[28] Gil B, Kasperski J. Efficiency analysis of alternative refrigerants for ejector cooling cycles. Energy Conversion and Management 2015;94:12-8.

[29] Chen J, Havtun H, Palm B. Screening of working fluids for the ejector refrigeration system. International Journal of Refrigeration 2014;47:1-14.

[30] Tashtoush B, Alshare A, Al-Rifai S. Performance study of ejector cooling cycle at critical mode under superheated primary flow. Energy Conversion and Management 2015;94:300-10.

[31] Hernandez JI, Roman R, Best R, Dorantes R, Gonzalez HE. The Behavior of an Ejector Cooling System Operating with Refrigerant Blends 410A and 507. Energy Procedia 2014;57:3021-30. 
[32] Gil B, Kasperski J. Performance estimation of ejector cycles using ethers and fluorinated ethers as refrigerants. Applied Thermal Engineering 2018;133:269-75.

[33] Kopchick S, Scancarello M. New Refrigerants Designation and Safety Classifications. E360 Forum 2017:1-28.

[34] Björn P. R1336mzz-Z - new generation nonflammable low GWP refrigerant. Department of Energy Technology, Royal Institute of Technology September 21, 2014.

[35] Atmaca AU, Erek A, Ekren O. Investigation of new generation refrigerants under two different ejector mixing theories. Energy Procedia 2017;136:394-401.

[36] Chen J, Havtun H, Palm B. Screening of working fluids for the ejector refrigeration system. International Journal of Refrigeration 2014;47:1-14.

[37] Honeywell Refrigerants. https://www honeywell-refrigerants com/europe/product/tag/allrefrigerants/ Accessed [16.04.2018].

[38] Eames IW, Aphornratana S, Haider H. A theoretical and experimental study of a small-scale steam jet refrigerator. International Journal of Refrigeration 1995;18:378-86.

[39] Volovyk OS. Improvement of characteristics and performances of an ejector refrigeration machine operating with low-boiling working fluids. Thesis, Odessa National Academy of Food Technologies, Ukraine 2013.

[40] Chen J, Havtun H, Palm B. Investigation of ejectors in refrigeration system: Optimum performance evaluation and ejector area ratios perspectives. Applied Thermal Engineering 2014;64:182-91.

[41] Huang BJ, Chang JM. Empirical correlation for ejector design. International Journal of Refrigeration 1999;22:379-88.

[42] Yen RH, Huang BJ, Chen CY, Shiu TY, Cheng CW, Chen SS et al. Performance optimization for a variable throat ejector in a solar refrigeration system. International Journal of Refrigeration 2013;36:1512-20.

[43] Engineering Equation Solver (EES). http://www.fchart.com/ees/. Accessed [01.06.2018]

[44] UNEP. HCFCs controlled under the Montreal Protocol. http://web2 unep fr/hcfc/about/default aspx?type=list Accessed [01.06.2018].

[45] BOC - A member of the Linde Group. Refrigerants. Product data summary. http://www lindegas com/internet global lindegas global/en/images/Refrigerants-Product-DataSummary17_108590 pdf?v=3 0 Accessed [01.06.2018].

[46] A-Gas(R). Product information guide. https://www agas co uk/media/3872/productinformation-guide pdf 2018; Accessed [01-06-2018].

[47] Wang JH, Wu JH, Hu SS, Huang BJ. Performance of ejector cooling system with thermal pumping effect using R141b and R365mfc. Applied Thermal Engineering 2009;29:1904-12. 